\title{
A Framework for Evaluating Land Use Planning Alternatives: Protecting Biodiversity on Private Land
}

\author{
$\underline{\text { David M. Theobald }}^{1}$ and $\underline{\text { N. Thompson Hobbs }}{ }^{2}$
}

\begin{abstract}
Planning activities by local government often seek to identify areas of land that offer particularly high value for conserving biotic resources. Because private land is being developed rapidly, there is heightened concern about identifying these areas. Although general principles on setting priorities for habitat protection are emerging, substantial ambiguity remains about how to implement these principles. Here, we offer a general modeling framework for evaluating how planning alternatives could affect Critical Habitat. The framework contains four components: stakeholder involvement, spatial modeling of Critical Habitat and development patterns, analysis of alternative scenarios, and evaluation and monitoring. We illustrate this approach using a case study from Summit County, Colorado, USA.
\end{abstract}

\section{INTRODUCTION}

Rapid development and landscape transformation of private land threatens efforts to conserve biotic resources throughout North America (Dale et al. 2000). Concern over loss of habitat is focused on private land, in large measure because listed species found on private land are declining more rapidly than those on public land (Noss et al. 1997), and because private land supports areas of particularly high biological diversity (Bean and Wilcove 1997). Fewer than $10 \%$ of endangered species occur exclusively on public land (GAO 1994). It follows that land use planning that affects private land is fundamentally important to conserving biological diversity nationwide (Beatley and Manning 1997, Dale et al. 2000).

Although scientists have begun to integrate ecological understanding into local land planning processes (Beatley 1994, McKinney and Murphy 1996, Crist et al. 2000, Theobald et al. 2000), important barriers to this integration remain. The most important impediment is conflict between objectives for human welfare and objectives for biotic conservation. As a result of this conflict, planners need ways to set priorities on conservation interests. Although there is heightened concern about private land use change and guiding principles are emerging (Duerkson et al. 1997, Dale et al. 2000), ambiguity remains about how to implement these principles.
A well-developed approach for land use planning examines the consequences of potential land use change on public lands by evaluating the relative impact of a range of alternative scenarios. For example, various alternatives are typically compared to examine the consequences of land use change on public lands (e.g., Federal Land Policy and Management Act). Alternative scenarios are beginning to be used to examine the consequences of private land use change on biological diversity as well (e.g., Hulse et al. 1995, Steinitz et al. 1996, White et al. 1997). Here, we further develop the use of alternative scenarios by providing a general framework that is explicitly linked to the local-level decision-making process. First, we describe the framework and how spatial models of biological resources and development are integrated into the framework. Next, we illustrate our approach using a case study in Summit County, Colorado, USA. Finally, we describe limitations of the approach and remaining practical challenges for conservation of biological diversity on private lands.

\section{METHODS}

There are four components to our modeling approach: stakeholder involvement, spatial description of biological diversity and development patterns, alternative scenario analysis, and evaluation and monitoring (Fig. 1). Critical to the success in implementing this framework is recognition of the 
decision-making context. A major challenge is to provide scientific information and analyses that can compete with various other objectives and information, such as impacts on traffic, school loading, and fiscal implications, that are brought together in the planning process (Rockwood 1995, McKinney and Murphy 1996). To assure that biological information is useful in local land use planning, it must be carefully linked to the decisions routinely made during the planning process (Cort 1996, Duerkson et al. 1997).

Fig. 1. There are four components of our framework for evaluating land use planning alternatives. First, stakeholder involvement is critical throughout the planning process and includes a series of meetings with planners, decision makers, and citizens to establish conservation goals, review spatial models, and identify feasible build-out scenarios. Second, spatial models of biological diversity and development patterns are developed based on the conservation goals and available data. Third, indicators of potential effects are analyzed for each build-out scenario. Finally, evaluation and monitoring of the conservation goals will allow for adaptive management.

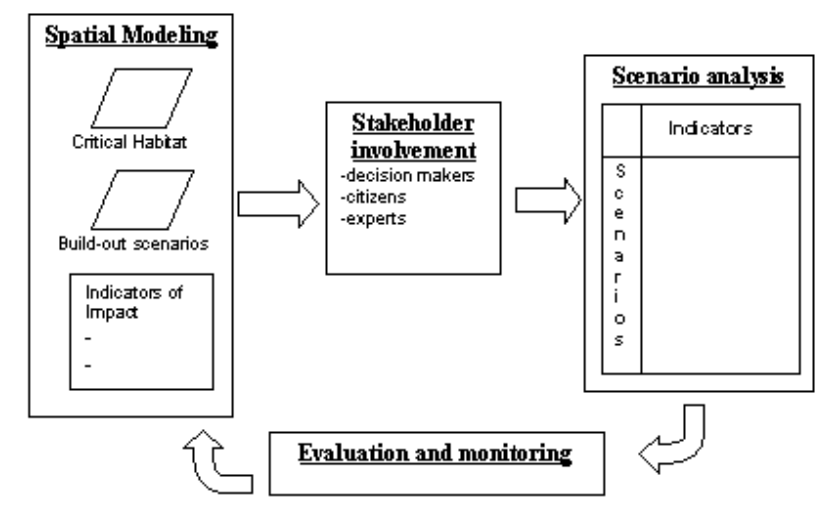

Two types of planning typically occur at the county level: site review and master planning. The site review process is triggered as individual developments and zoning changes are proposed. During site review potential impacts on habitat are considered alongside other factors such as compliance with zoning, adequate water supply and sewage disposal, compatibility with soils, topography, and hazards, adequate access to transportation systems, and maintenance of affordable housing. Master or comprehensive planning provides a countywide "vision" and establishes the goals and policies for long-term land use decisions. These master plans are usually advisory, not regulatory, and the implementation of policies of the master plan depends largely on the political will of the locally elected officials and the support of their constituency. Master plans are also important because they typically guide policy beyond the tenure of individual officials. The framework described here is designed to inform the master planning process, although products from it are useful during site-review as well.

\section{Stakeholder involvement}

The first component of the modeling framework is stakeholder involvement. Stakeholders for local land use planning typically include decision makers (e.g., county commissioners, planning and zoning board members), their staffs (e.g., planners), and citizens who wish to influence the outcome of decision-making processes (e.g., environmental advocates, landowners, developers, neighbors). Biologists are also involved, providing expert knowledge and recommendations to the stakeholder group. Aspects of effective stakeholder interaction are outlined by Shindler and Cheek (1999).

Stakeholders are an integral part of the framework, and they provide four important functions. First, stakeholders establish conservation goals. Examples of such goals might be maintaining the abundance of a set of indicator species, protecting representative areas of plant communities, preserving current levels of species richness in targeted areas of a landscape, or restoring species that have been extirpated. Stakeholders help to identify species that are valued by the local community and to establish their relative importance. This step also helps to prioritize new data collection to fill data gaps on particular species that are important to the local community. Second, through detailed review of the results of the second component (spatial models of biological value and development patterns), stakeholders are able to frame and refine the spatial modeling process. In conjunction with biological experts, the credibility of the Critical Habitat maps can be established, which is needed for the process to succeed in a public review process. Third, stakeholders help to assemble a list of up to 12 alternative build-out scenarios. To be useful, each alternative should reflect a planning action that is realistic and politically feasible, should be based on reasonable modeling assumptions, and should be grounded in available spatial data. Fourth, stakeholders filter the preliminary list of indicators of impact. Importantly, stakeholders must be able to 
readily understand how each indicator is calculated and how it responds to different situations of development patterns and Critical Habitat. Finally, stakeholders choose indicators of success, which become critical in designing evaluation and monitoring procedures.

\section{Spatial modeling}

The second component of the framework is a set of spatial models that provide a scientific basis for land use decision making. There are three parts to this component: mapping Critical Habitat, developing alternative development scenarios, and building a list of potential indicators of impact. These maps must be easily understandable and interpretable by managers, decision makers, and the public (Meredith 1996, Theobald et al. 2000).

A central challenge in conservation planning is to identify areas that are critical to the conservation of biodiversity. Mapping these areas requires numerous compromises, and the practical reality of most planning situations is that there are limited spatial data to work with. For example, the distributions of only about $10 \%$ of the 225 vertebrates found in Colorado have been mapped (not to mention invertebrates and plants), and these maps are often fairly subjective. Also, it is important to sift through available data to determine which areas are really critical. Even though an entire county or planning area may contain habitat, rather than "painting the whole county red," areas need to be targeted on the basis that their loss would limit the abundance and/or presence of a species. In fact, identifying areas that are not important to maintaining biodiversity often is an effective strategy. Identifying which areas to protect relies on clearly defining the species and the goals for species that should be protected. Because this is a value-laden process, it is important for the decision makers and citizens to articulate clearly what individual species and/or communities and what attributes (e.g., viable population, abundance, etc.) they are concerned about.

The approach that we advocate is to produce a "Critical Habitat Map" identifying areas of critical concern for conserving wildlife and natural communities. The Critical Habitat map is composed of four individual maps that identify areas containing rare vegetation types, known areas of sensitive and rare species, areas of high neighborhood diversity, and habitat of economically important species. The composite Critical Habitat map has values ranging from 0 (no critically important areas) to 4 (four indices identify its importance). This approach balances information about known distributions of species with information about potentially suitable habitat. It is important to remember that, because species distributions may change, data depicting distributions must be updated on a regular basis.

Build-out scenarios are used to examine probable future development intensities and patterns. Two products of a build-out analysis are (1) maps that show development patterns reflecting different assumptions and (2) tables quantifying the number of new units, residents, and acreage consumed. These patterns show what would probably result if development were to continue according to current zoning ordinances and subdivision regulations until there were no more parcels to build on (Lacy 1992). Build-out maps help citizens and officials to visualize the likely future development patterns for their community, to provide a graphic depiction of the areas of land that are most likely to be impacted by development. These maps often reveal that zoning alone does not adequately protect all human and biotic values in a landscape, as is often assumed by residents and officials (Arendt 1996).

Typically, a build-out scenario is created by calculating the number of total building units that can be built on a parcel, as prescribed by zoning regulations (Lacy 1992). Different scenarios are usually compared to evaluate planning policies and growth trends. There are a number of different approaches to creating alternative development scenarios (e.g., Lacy 1992, Landis 1995, Klosterman 1999). Here, we extend previous build-out analysis methods to utilize GIS technology, using a simple model, and to examine implications for biological resources. One advantage of build-out analysis is that the emphasis is placed on examining development patterns produced by current regulations and policies, that is, the endpoint of growth. This approach is much different than modeling the trends of growth (the path of growth over time), where more emphasis is placed on identifying the locations of development at a series of intervals (e.g., 5 years) through time (e.g., Landis 1995, Theobald and Hobbs 1998).

In addition to producing a series of maps depicting the development patterns for each build-out scenario, it is necessary to develop a list of indicators that could be used to evaluate the landscape-level effects of development. The list of indicators is initially 
compiled to address important principles of conservation biology, landscape ecology, and land use planning, especially quantifying habitat loss, degradation, and fragmentation. Although there are numerous potential indicators that can be used, we suggest the following. First, the total number of units predicted under each scenario is a rough indicator of overall impact. By itself, this measure poorly reflects the differential impact associated with different development patterns and density. However, it is needed as a reference variable so that the difference in area of Critical Habitat impacted can be examined with respect to the number of housing units. Also, it is the primary variable for the stakeholders to begin evaluating scenarios. Second, the total length of roads required to service development, excluding the primary road infrastructure, indicates the magnitude of impacts associated with roads (Forman and Alexander 1998). Third, the total acreage of Critical Habitat that is affected by development is perhaps the most direct indicator of impact. To account for the varying effects of different levels of housing density, we translate housing density into the proportion of a parcel that is affected by the zone of disturbance surrounding each housing unit. The zone of disturbance is calculated by assuming that changes in native vegetation and vegetation structure, predation from domestic pets, and wildlife behavior reduces the availability of habitat in the area surrounding a house (Theobald et al. 1997). Typically, we use a building effect distance of $100 \mathrm{~m}$ when calculating the zone of disturbance, although impacts of between 200 and $800 \mathrm{~m}$ have been documented for a range of species (Theobald et al. 1997). Even at a distance of $100 \mathrm{~m}$, the percentage within the disturbance zone increases rapidly with increasing density, so that a density of 1 unit per 35 acres [conversion: 1 acre $=0.405$ ha] results in $20 \%$ of the parcel being affected, whereas a density of 1 per 10 acres results in $77 \%$ of the parcel being affected (see Table 1).

Table 1. Percentage of a parcel within $100 \mathrm{~m}$ of development at different building densities. The area within this distance is called the disturbance zone.

\begin{tabular}{ccc}
\hline Housing density (no. ha per unit) & Housing density (no. acres per unit) & $\begin{array}{c}\text { Percentage of parcel } \\
\text { within } 100 \mathrm{~m}\end{array}$ \\
\hline$<1.0$ & $<2.5$ & 100 \\
$1.0-4.0$ & $2.5-10$ & 77 \\
$4.0-8.1$ & $10-20$ & 39 \\
$8.1-16.2$ & $20-40$ & 20 \\
$>16.2$ & $>40$ & 10
\end{tabular}

Habitat fragmentation is an important threat to biodiversity and is characterized as the break up of a continuous landscape containing large habitat patches into smaller, usually more numerous and less connected patches (Noss et al. 1997). Many measures have been developed to calculate aspects of fragmentation, including core area and relative size of the largest patch (Turner et al. 2001). However, in practice, it is difficult to develop a single indicator because we must deal with broad assemblages of species and communities in private land use planning (Theobald 2000), yet fragmentation is species- and landscape-specific (Tischendorf and Fahrig 2000). Recognizing these limitations, our approach here was to measure fragmentation in a general way and to ensure that small changes in the way in which Critical Habitat patches and development were defined did not lead to large changes in our metric. We chose to calculate the average distance of locations of Critical Habitat to the nearest "developed" location, a slight modification of the GISFrag index of Ripple et al. (1991). This is computed by calculating, for each pixel of Critical Habitat, the distance to the nearest parcel that reaches a specific density (e.g., urban areas). We arbitrarily established housing density thresholds at urban density ( $>1$ housing unit per 0.8 ha) and exurban density ( $>1$ housing unit per 16.1 ha). 
Although the main emphasis of this paper is to evaluate the broad-scale effects of development, these data can also be used to identify specific locations of concern. That is, individual parcels can be identified for which a wide range of impacts were predicted under different scenarios; these can be used to finetune the location where each planning policy should be targeted. Also, parcels that are likely to have a large effect in all scenarios can be identified to target locations where other means of protection, such as conservation easement or purchase, is needed. Finally, parcels with a large proportion coinciding with Critical Habitat $(\mathrm{CH})$ can be flagged for closer inspection during site-level development review.

\section{Scenario analysis}

The third component of the framework is an analysis of the consequences of different build-out scenarios on the Critical Habitat areas, as computed by the indicators of impact. A typical format to present results of the analysis is a matrix (or table) containing the various indicators scored for each scenario. This allows one to examine how different indicators vary in response to different planning scenarios. These scenarios can then be compared and evaluated to determine which planning action might reduce or limit the impact on Critical Habitat. Typically, this information is presented not only in a technical report, but also in public "open houses" and at commissioner hearings. Scenario analysis is an important way to summarize detailed biological information, and it is a key information product that can be used to inform the local-level decision-making process.

\section{Evaluation and monitoring}

One of the main motivations for stakeholder involvement is to set standards for success in conservation plans. These goals become critical in designing ways to monitor and evaluate conservation plans. Monitoring schemes must translate the goals specified in conservation plans into measurements that can be taken remotely or in the field. Inventories could include estimates of abundance of selected species, measurements of an area of land in some identified vegetative condition, counts of species of plants or animals per unit area of habitat, or estimates of vital rates of populations. Investment in these measurements allows for adaptive management at local scales (Holling 1978, Walters 1986, Lee 1993, Haney and Rebecca 1996, Ringold et al. 1999). Conservation plans can be adjusted if they fail to meet goals, as indicated by ongoing monitoring and evaluation.

Fig. 2. Summit County is located in central Colorado, USA, along the continental divide, about 60 miles [97 km] from Denver. It is home to the towns of Breckenridge, Keystone, Frisco, and Silverthorne.

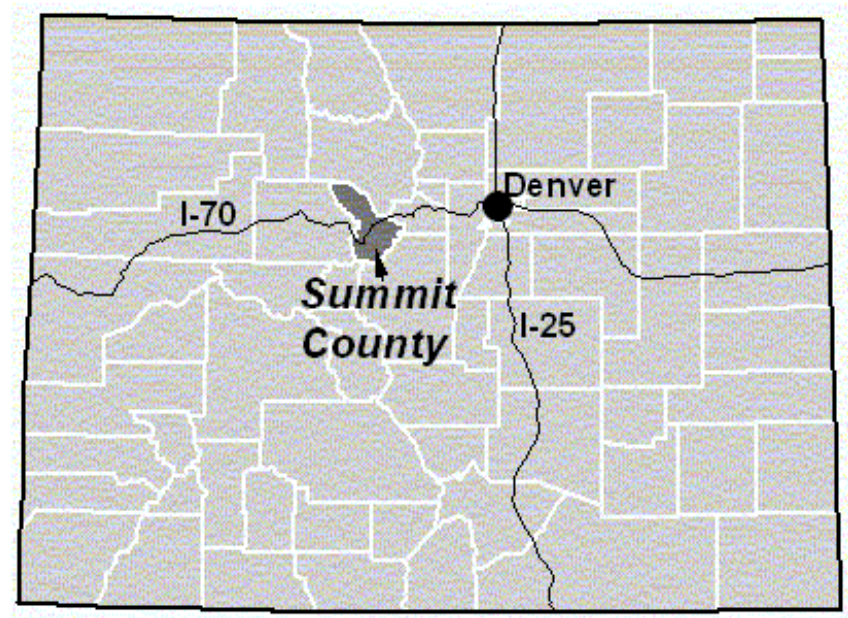

Fig. 3. An aerial view of Summit County looking northeast over Frisco toward Silverthorne. Interstate 70 and Dillon Reservoir are clearly visible. The Lower Blue Planning Basin begins to the left (north) of Interstate 70. The photo was taken by Bob von Normann, OImpact Colorado.

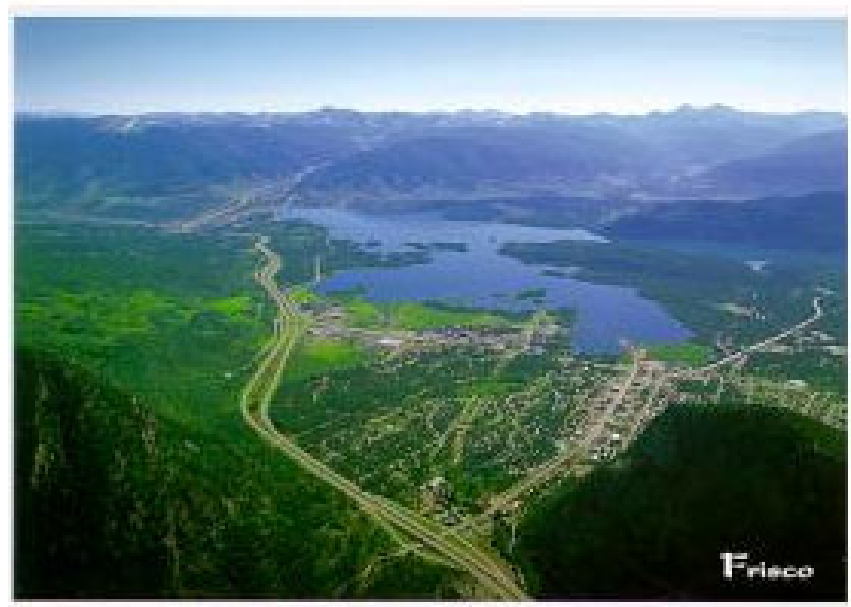


Fig. 4. Nearly all of the private land in Summit County is confined to the narrow valley bottoms. The remainder of the county (about $80 \%$ ) is public land (shown in gray). The Lower Blue Planning Basin occupies $722 \mathrm{~km}^{2}(178,400$ acres) in the northern part of the county. Most of the higher density zones are located in the south near the Town of Silverthorne, whereas lower density zones are located down-valley (to the north).

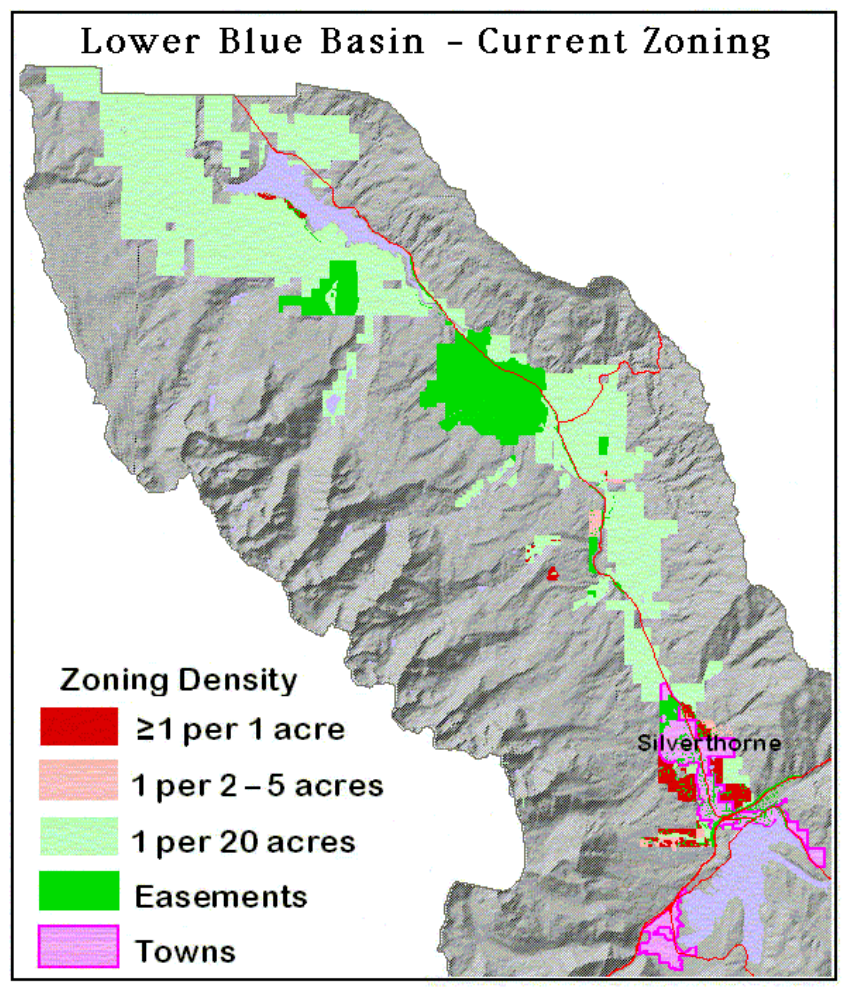

\section{CASE STUDY}

We illustrate this general approach using a case study in Summit County, Colorado, USA, which is located about 60 miles $[96.6 \mathrm{~km}$ ] west of Denver on US Interstate 70 and contains the mountain resorts of Breckenridge, Vail, and Keystone (Fig. 2 and Fig. 3). Summit County has grown rapidly, tripling its population since 1975. The Lower Blue Planning Basin (LBPB) is the least developed portion of Summit County and is also the richest in terms of biological resources (Fig. 4). Potential impacts of development on wildlife habitat and biodiversity in Summit County are written into the Land Use Code (Summit County 2000, §4201):

The Summit County Board of County Commissioners finds that there are areas in the County that contain wildlife habitats and wildlife species, a natural resource of local, statewide, national and global significance. The diversity of wildlife species and habitat that occur in the County should be maintained and enhanced in order to promote the health, prosperity and welfare of the present and future inhabitants of the State and Summit County in particular. In addition, Colorado law (C.R.S. 29-20104(b)) gives broad authority to local governments in Colorado to plan for and regulate the use of land to protect the environment and protect land from activities which would cause immediate or foreseeable danger to significant wildlife habitat and would endanger a wildlife species. To this end, land uses and development should be planned and designed to be harmonious with wildlife habitat and the species that depend on this habitat, and should recognize and protect the full range of habitats and species in the County. Wildlife habitat includes areas important for the full range of aquatic, terrestrial, game and non game species. These habitats are inhabited or have the potential of being inhabited by wildlife species that provide economic, recreational and environmental benefits to the residents and visitors of Summit County.

\section{Stakeholder involvement}

In Summit County, we used a process that we called "collaborative design" to identify conservation goals. The people involved in this process included a county commissioner, a planner, a developer, a land owner, a wildlife manager, and some environmental advocates. Technical expertise was contributed by ecologists, geographers, a land use attorney, and computer programmers (Theobald et al. 2000). We began with a day-long "primer" workshop in which we established a shared understanding of land use planning in Summit County. In addition, this primer meeting reviewed general principles of conservation biology and outlined the biological data sets available to us. We covered aspects of human geography relevant to growth locally and regionally. Each of the primers was led by one or more stakeholders with expertise in that area.

Over the course of the subsequent year, we held nearly a dozen work sessions with the design group, iteratively identifying goals and evaluating data needs. Most of the organization and logistical arrangements were driven by the scientists. The primary role of the scientists was to facilitate discussion and invoke needs from the rest of the stakeholders. We found that a change in meeting venue (i.e., from county courthouse to Federal offices to private residence) balanced the discussion. 
Although the collaborative design process was time consuming, we considered it very worthwhile. Each critical decision in the design of biological information systems was informed by an understanding of the planning context and a "real-life" example of information needs. This process also provided a way to pre-test the design of our system.

During these meetings, the team identified conservation of biodiversity as the top goal, along with maintenance of species important to their economy, which traditionally have been game species (e.g., elk, deer, trout, etc.), but increasingly includes "watchable" species (e.g., hummingbirds, wildflowers). To this end, we focused on species that are either particularly sensitive to human impacts or are economically important. Sensitive species include those identified in state or federal lists as threatened or endangered, species that the Colorado Natural Heritage Program (CNHP) considers imperiled, species that are in notable decline as determined by the Colorado Vertebrate Ranking System, and Colorado Division of Wildlife Species of Special Concern (Hobbs et al. 1998). The design team also provided review and feedback on the spatial modeling process, and a subsequent wildlife task force also evaluated and compared this habitat mapping process with other counties around the state.

An important issue that the scientists pursued with the stakeholders throughout the meetings was the adequacy and usefulness of the typical approach of preparing maps of all species found in the county, and complementary models depicting how development would impact species' habitat. One of the key information needs was a list of species found in a given area, such as threatened and endangered species, economically important species, declining species, all vertebrate species, etc., to establish priorities for species protection (Theobald et al. 2000). Scientists felt that a quantitative index, such as the proportion of species found in a county that occupy at a given location, would be a useful, robust indicator. However, most of the stakeholders argued that they had difficulty in evaluating the relative importance of one species over another. Our compromise solution was to identify groups of species and ways of classifying the landscape to represent different aspects that the stakeholders valued and that the scientists felt were important from general conservation ecology principles. We settled on four aspects of the landscape, which are reflected in the spatially explicit models that we will describe.
An important role for us as scientists in the stakeholder process was to act simultaneously as experts and as filters to scientific information. Scientists are trained and rewarded for staying abreast of the latest findings and approaches, operating in a rich environment with numerous, often competing, ideas. Scientists are relatively comfortable with sorting through a number of alternative viewpoints, and are adept at manipulating complex equations. However, we were challenged by the stakeholders to select from the richness of the ecological literature to identify the salient factors, to simultaneously appreciate the complexity of the current state of ecological knowledge, yet to be comfortable with simplifying it to a large degree.

Fig. 5. Map of rare vegetation types (shown in green) in Summit County, Colorado. These include types that make up less than $3-5 \%$ of the total area on an individual basis. This map include areas identified as Aspen, Willow, Sage, and Water from a classified Landsat TM image (30-m resolution) and wetlands identified using low-altitude aerial photography.

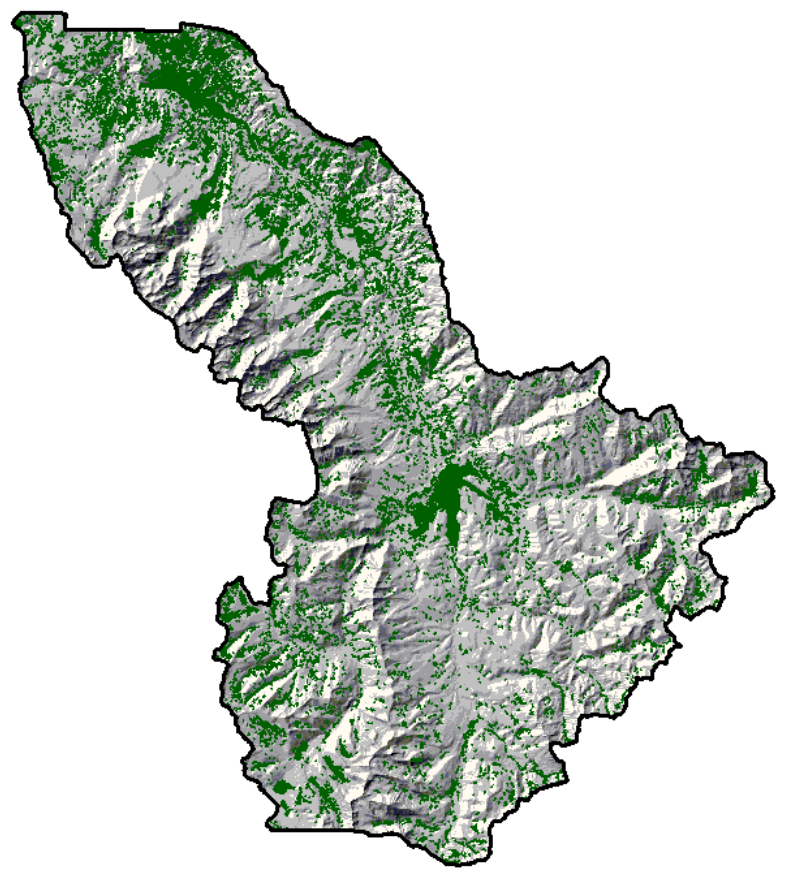

\section{Spatial modeling}

We worked with the stakeholders in Summit County to develop a Critical Habitat map. Critical Habitat $(\mathrm{CH})$ is composed of four individual maps that identify areas containing rare vegetation types, known areas of 
sensitive and rare species, areas of high neighborhood diversity, and habitat of economically important species.

Fig. 6. Map of sensitive and rare species habitat (shown in green) in Summit County, showing known locations of habitat for species listed as federally and state "threatened and endangered" and state "species of special concern," using data from the Colorado Division of Wildlife and the Colorado Natural Heritage Program's potential conservation areas and element occurrences (with a 400-m buffer).

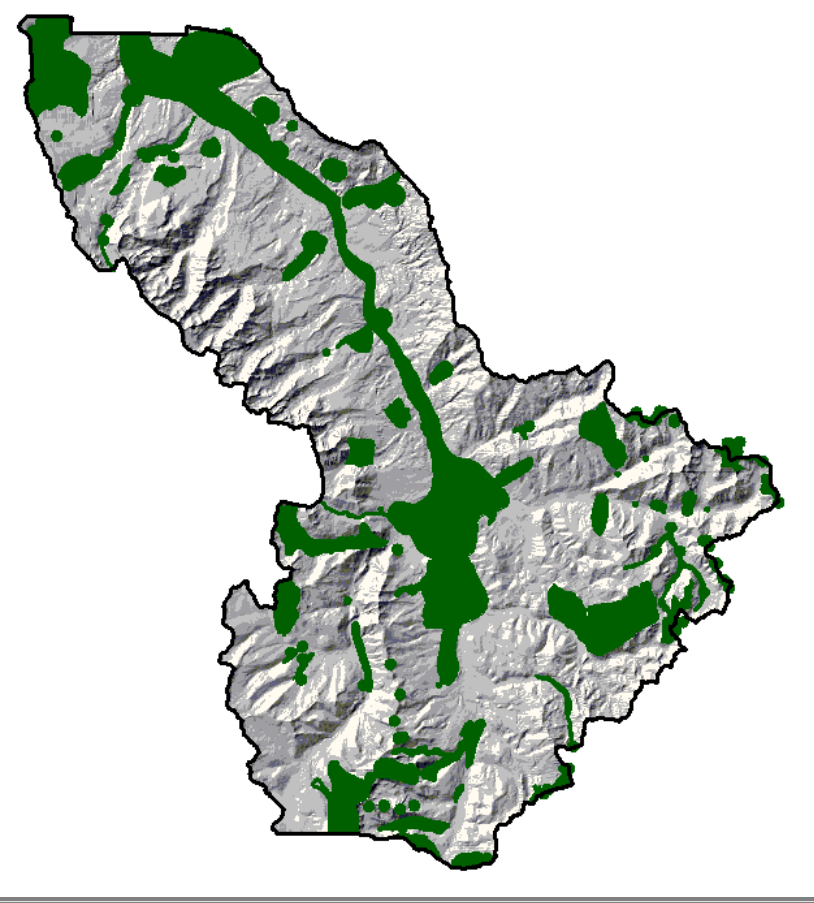

Rare vegetation types: This map identifies locations that contain rare vegetation types, which we defined as those types that typically make up $<3-5 \%$ of the total area on an individual basis (Fig. 5). Two types of data were used to map rare vegetation. First, we included Aspen, Willow, Sage, and Water from a land cover map produced from a classified Landsat TM image (30-m resolution). We also included wetlands identified in a detailed $(<1: 24000)$ mapping effort, produced from interpretation of low-altitude aerial photography.

Sensitive and rare species: This map shows known locations of habitat for species listed as federally and state threatened and endangered, and state species of special concern (Fig. 6). Data come from the Colorado Division of Wildlife's habitat maps (Table 2), as well as CNHP's potential conservation areas and element occurrences (with a 400-m buffer). The boundaries of potential conservation areas are drawn to include the ecological processes needed to sustain the imperiled species found in an area (Stein et al. 1999). Note that Sage Grouse is likely to be moved in the near future from the "economically important species" map to this map.

High neighborhood species richness: This map identifies locations that are among the top $10 \%$ of the county in neighborhood species richness (Fig. 7). This map is produced by combining the modeled distributions for 103 vertebrate species found in Summit County that are listed as sensitive (USDA Forest Service), as threatened or endangered (federal or state government), as species of special concern (by the state ), as imperiled (CNHP 1999), or as economically important. The richness value for each species was weighted by its biological rarity (Gross and Melcher 1998). We then found the areas that contribute to the top $10 \%$ in weighted-species richness.

Fig. 7. Map of high neighborhood species richness (shown in green) in Summit County, Colorado. This map identifies locations that are in the top $10 \%$ of the county in neighborhood species richness. The modeled distributions for 103 vertebrate species were weighted by the biological rarity of each species.

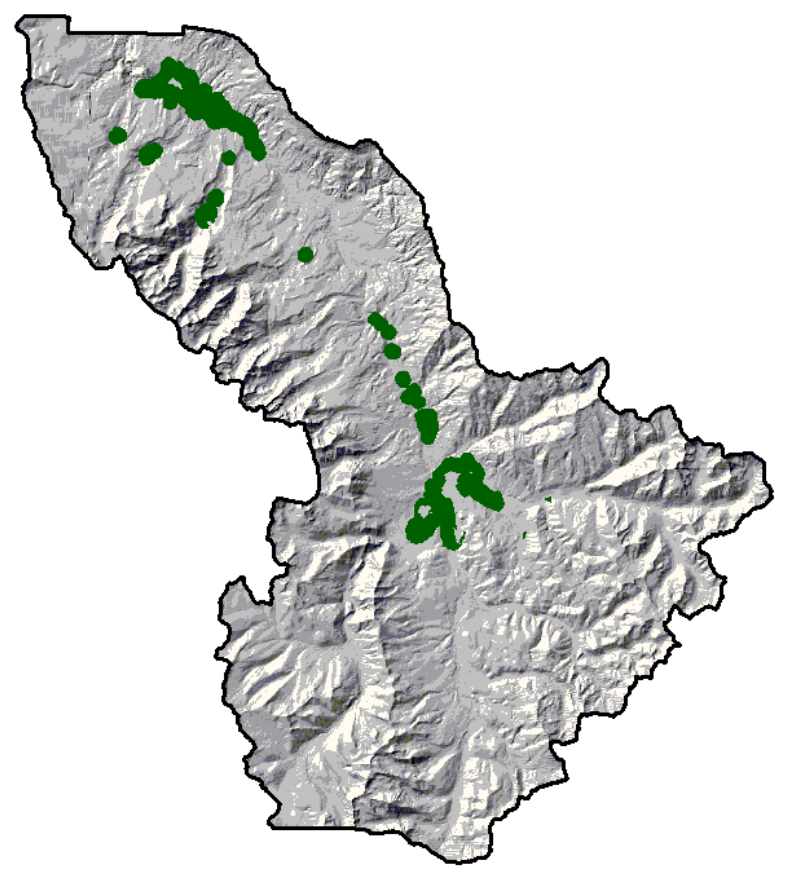


Table 2. Spatial data available for Summit County depicting the known distributions of sensitive and rare species.

\begin{tabular}{|c|c|c|c|}
\hline Species & Status $^{\mathrm{a}}$ & Activity area & Description \\
\hline $\begin{array}{l}\text { Bald Eagle } \\
\text { Haliaeetus leucocephalus }\end{array}$ & $\begin{array}{l}\text { FT, ST, } \\
\text { G4, S1 }\end{array}$ & winter range & $\begin{array}{l}\text { Areas where bald eagles have been observed between } 15 \\
\text { November and } 1 \text { April. }\end{array}$ \\
\hline $\begin{array}{l}\text { Boreal toad } \\
\text { Bufo boreas boreas }\end{array}$ & $\begin{array}{l}\text { FC, FS, } \\
\text { SE, G4, } \\
\quad \text { S1 }\end{array}$ & occurrences & $\begin{array}{l}\text { All locations with documented observation of any life stage of } \\
\text { boreal toad (toads, tadpoles, eggs). Locations represented as } \\
\text { point data, with 200-m buffer for protection. }\end{array}$ \\
\hline $\begin{array}{l}\text { Colorado River cutthroat trout } \\
\text { Oncorhynchus clarki } \\
\text { pleuriticus }\end{array}$ & $\begin{array}{l}\text { FS, SC, } \\
\text { G4, S3 }\end{array}$ & $\begin{array}{l}\text { purity A and B } \\
\text { (buffered by } \\
100 \mathrm{~m} \text { ) }\end{array}$ & $\begin{array}{l}\text { Distribution of A and B purity grades of Colorado River } \\
\text { cutthroat trout. }\end{array}$ \\
\hline $\begin{array}{l}\text { Golden Eagle } \\
\text { Aquila chrysaetos }\end{array}$ & - & nest sites & $\begin{array}{l}\text { Location and buffer zone extending } 0.25 \text { mile }[0.4 \mathrm{~km}] \text { around } \\
\text { known active or inactive nest. Inactive nests were documented } \\
\text { in past } 10 \text { years as having been used in nesting attempts, with } \\
\text { egg-laying at least. }\end{array}$ \\
\hline $\begin{array}{l}\text { Northern Goshawk } \\
\text { Accipiter gentilis }\end{array}$ & $\begin{array}{l}\text { FS, G5, } \\
\quad \text { S3 }\end{array}$ & sites & $\begin{array}{l}\text { Specific location where a pair of goshawks has at least tried to } \\
\text { nest within last five years. Any nest directly tied to courtship, } \\
\text { breeding, or brooding behavior is considered active. Buffer } \\
\text { zone of } 0.25 \text { mile extends around active nest site. }\end{array}$ \\
\hline $\begin{array}{l}\text { Osprey } \\
\text { Pandion haliaetus }\end{array}$ & $\begin{array}{l}\text { FS, G5 } \\
\quad \text { S3 }\end{array}$ & $\begin{array}{l}\text { active nest } \\
\text { sites }\end{array}$ & $\begin{array}{l}\text { Specific location in which a pair of Osprey has at least tried to } \\
\text { nest within last five years. Any nest directly tied to courtship, } \\
\text { breeding, or brooding behavior is considered active. Buffer } \\
\text { zone of } 0.25 \text { mile extends around active nest site. }\end{array}$ \\
\hline $\begin{array}{l}\text { Otter } \\
\text { Lutra canadensis }\end{array}$ & $\begin{array}{l}\text { SE, G5, } \\
\text { S3, S4 }\end{array}$ & $\begin{array}{l}\text { overall range } \\
\text { and sightings }\end{array}$ & $\begin{array}{l}\text { An area that encompasses all mapped seasonal activity areas } \\
\text { within observed range of population of river otters. }\end{array}$ \\
\hline $\begin{array}{l}\text { White-tailed Ptarmigan } \\
\text { Lagopus leucurus altipetens }\end{array}$ & G5, S4 & $\begin{array}{l}\text { winter } \\
\text { concentration } \\
\text { areas }\end{array}$ & $\begin{array}{l}\text { Part of winter range where bird densities are at least twice } \\
\text { those of surrounding winter range. Winter range is defined as } \\
\text { locations of birds from late October to late May. }\end{array}$ \\
\hline
\end{tabular}

${ }^{\text {a }}$ Status codes (CNHP 1999):

FC, Listed as a candidate species by USFWS.

FS, Listed as a sensitive species by BLM and/or USFS.

FT, Listed as a threatened species by USFWS.

G4, Ranked by Colorado Natural Heritage Program as apparently secure globally.

G5, Ranked by Colorado Natural Heritage Program as demonstrably secure globally.

S1, Ranked by Colorado Natural Heritage Program as critically imperiled statewide.

S3, Ranked by Colorado Natural Heritage Program as vulnerable statewide.

S4, Ranked by Colorado Natural Heritage Program as apparently secure statewide.

SC, Listed by the Colorado Division of Wildlife as a species of special concern.

SE, Listed by the Colorado Division of wildlife as an endangered species.

ST, Listed by the Colorado Division of wildlife as a threatened species. 
Table 3. Spatial data available for Summit County depicting the known distributions of economically important species.

\begin{tabular}{|c|c|c|}
\hline Species & Activity area & Description \\
\hline $\begin{array}{l}\text { Elk } \\
\text { Cervus elaphus }\end{array}$ & severe winter range & $\begin{array}{l}\text { That part of a species'range where } 90 \% \text { of individuals are located when the } \\
\text { annual snowpack is at maximum and/or temperatures are at minimum in the } \\
\text { two worst winters out of 10; e.g., severe winter of 1983-1984. }\end{array}$ \\
\hline $\begin{array}{l}\text { Mountain goat } \\
\text { Oreamnos } \\
\text { americanus }\end{array}$ & $\begin{array}{l}\text { production } \\
\text { areas }\end{array}$ & $\begin{array}{l}\text { That part of home range of mountain goat occupied by females between } 15 \\
\text { May and } 30 \text { June. }\end{array}$ \\
\hline $\begin{array}{l}\text { Mule deer } \\
\text { Odocoileus } \\
\text { hemionus }\end{array}$ & severe winter range & $\begin{array}{l}\text { That part of the overall range where } 90 \% \text { of the individuals are located when } \\
\text { annual snowpack is at its maximum and/or temperatures are at a minimum in } \\
\text { the two worst winters out of } 10 \text {. }\end{array}$ \\
\hline $\begin{array}{l}\text { Sage Grouse } \\
\text { Centrocercus u. } \\
\text { urophasianus }\end{array}$ & overall range & $\begin{array}{l}\text { An area that encompasses all mapped seasonal activity areas within the } \\
\text { observed range of a population of Sage Grouse. }\end{array}$ \\
\hline
\end{tabular}

Fig. 8. Map of economically important species habitat (shown in green) in Summit County, Colorado. This map identifies critical ranges for species important to the local economy.

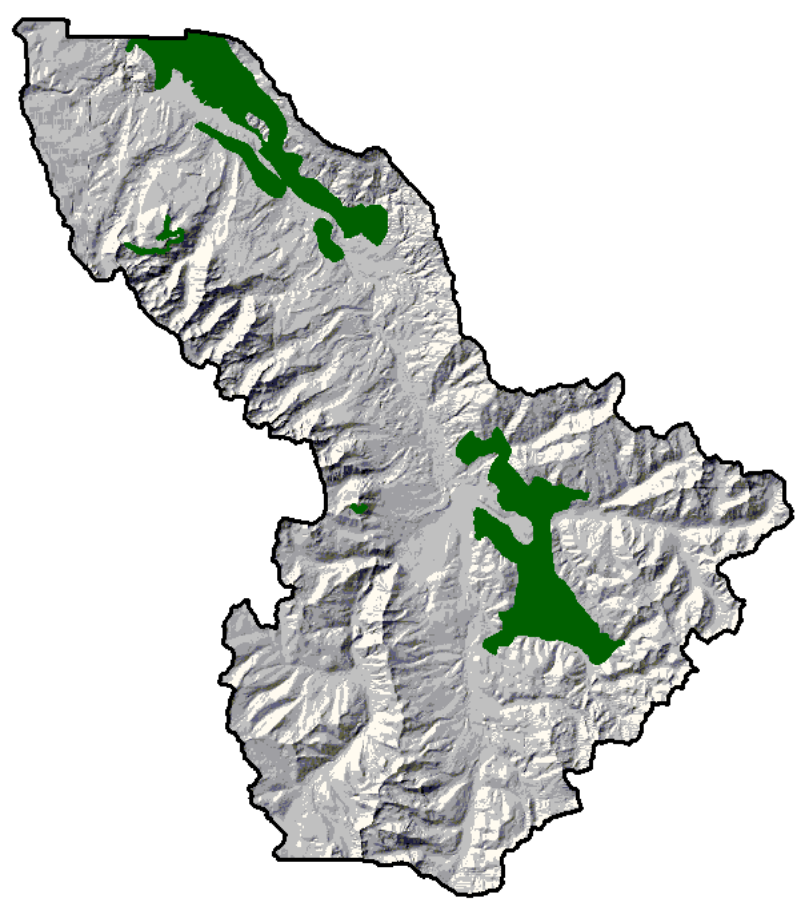

Fig. 9. Map of composite Critical Habitat maps in Summit County, Colorado. The individual map layers from the rare vegetation, sensitive and rare species habitat, high neighborhood richness, and economically important species habitat were overlayed to create the composite Critical Habitat map. Areas identified in one component are shown in light green, areas identified with up to four components are shown in dark green.

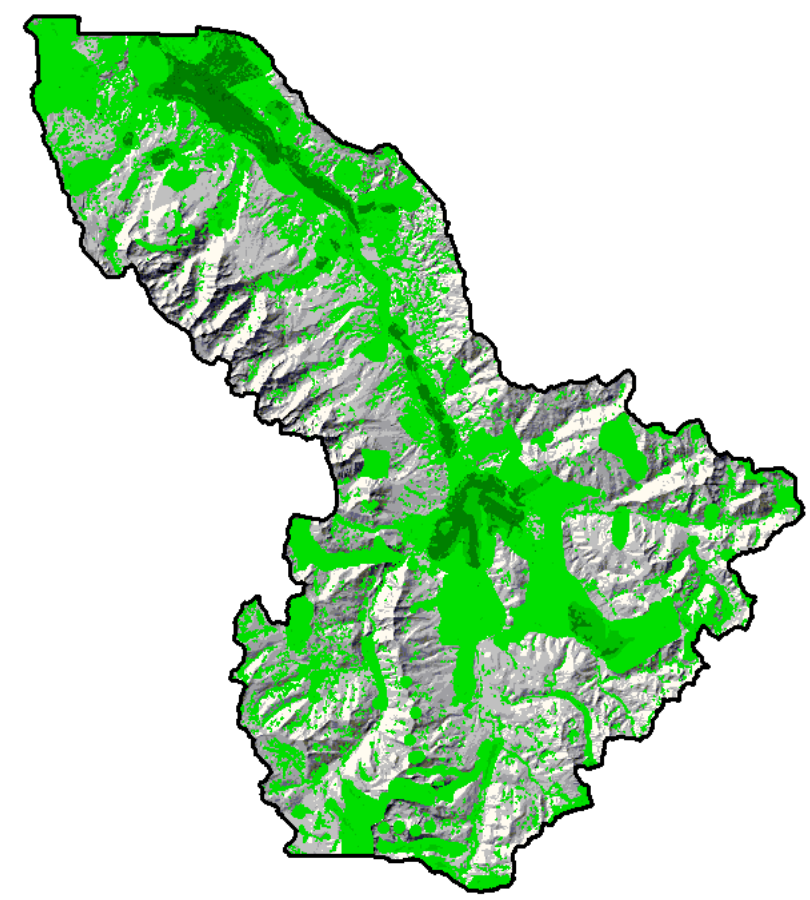


Economically important species: This map identifies critical ranges for species important to the local economy (Table 3 and Fig. 8). Data are from the Colorado Division of Wildlife's WRIS database, mapped at 1:50000 scale. We then overlayed the four component maps to create the composite Critical Habitat (CH) map (Fig. 9).

We developed a range of scenarios for the Lower Blue Planning Basin (LBPB) that reflected not only baseline conditions, but also a number of regulations and development trends that probably will affect the development patterns. These scenarios were compared to the current (1999) pattern of development (Fig.10). All scenarios do not incorporate potential future units that are available to be built inside the Town of Silverthorne's current city limits.

Fig. 10. Development in the Lower Blue Planning Basin in 1999. For each parcel (not shown) in the private land (shown in pink), the number of units in each parcel is portrayed by randomly placing one point or dot per unit inside the parcel polygon. Each dot represents one housing unit, such as a condominium or single-family residence. For small parcels (e.g., near Silverthorne) the dots coalesce, so very densely settled areas will have many dots stacked on top of one another.

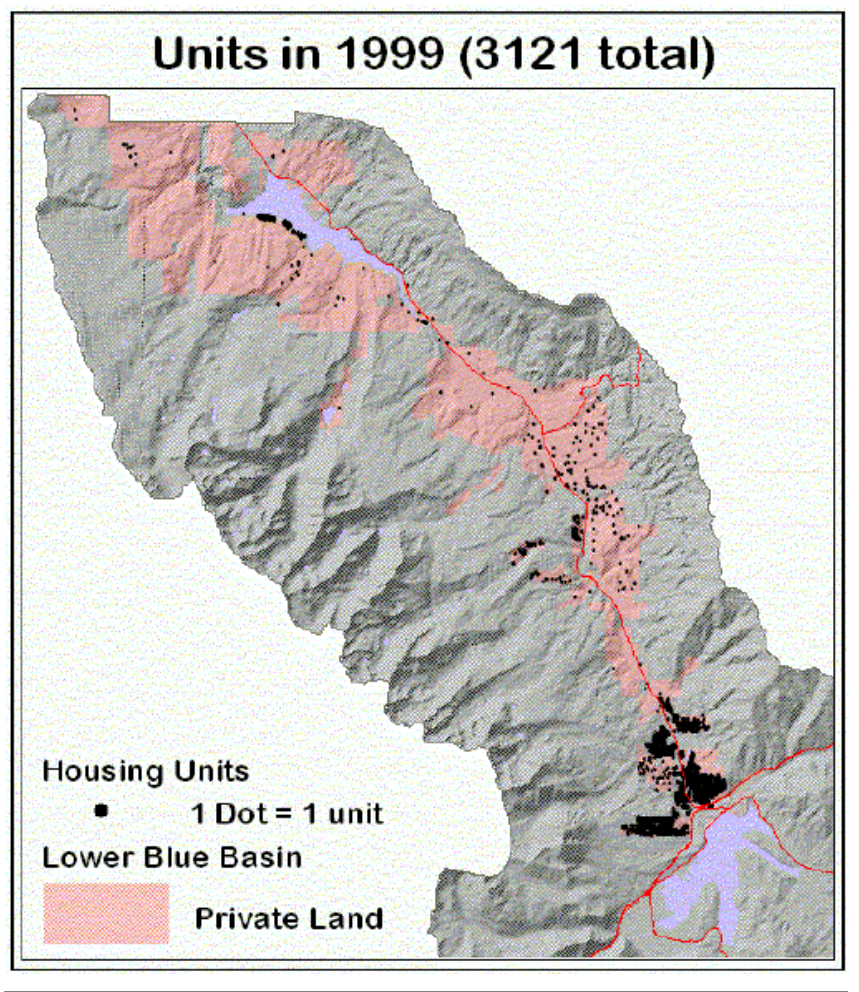

Complete Build-out (total acres): This is the baseline scenario in which we assumed that development will utilize all possible units allowed under the zoning regulations currently in place (Fig. 11). For each parcel, the possible number of additional units was calculated, given the size of the parcel, the number of current units, and the zoning designation. Parcel maps need to be checked to remove parcels that may have a zoning designation but are right-of-ways (roads), public lands, parks or open space, or owned by homeowner associations. Also, some parcels may have conservation easements on them that may limit the number of housing units that can be built. A further complication, especially when calculating parcel acreage, is that a parcel is not always represented by a single polygon, or even adjacent polygons, in a parcel map. Occasionally, parcels are represented by separate, disjunct polygons (e.g., split by a road rightof-way) and must be combined prior to calculation of build-out units.

Fig. 11. Development in the Lower Blue Planning Basin allowed under current zoning (scenario CB, Complete Build-out). Note that a large portion of the LBPB can be developed at low densities (one unit per 20 acres [8.1 ha]). For each parcel (not shown) in the private land (shown in pink), the number of units in each parcel is portrayed by randomly placing one point or dot per unit inside the parcel polygon.

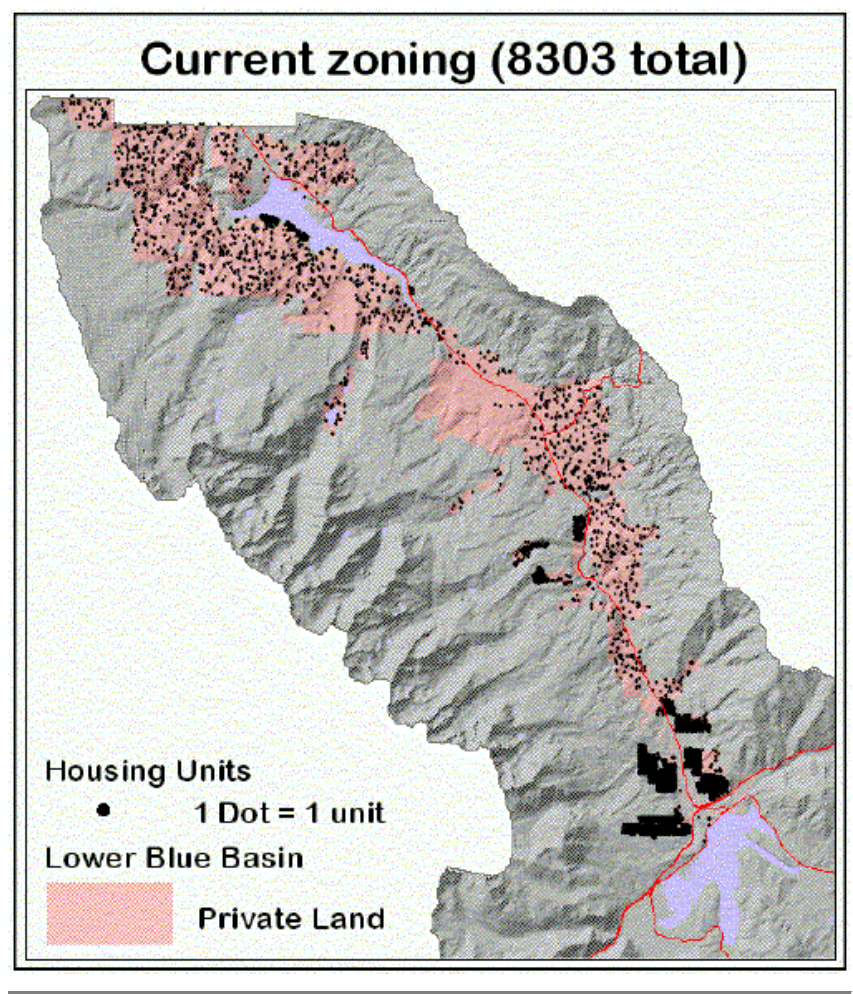

To calculate the build-out units, we first created a table that had all possible zoning designations and calculated the number of units per acre that were allowed for each zone (e.g., if 1 unit per 20 acres, then 
there are 0.05 units per acre; 1 acre $=0.405$ ha). Next, we joined the zoning table to the parcel map, using zone as the common attribute. If the parcels did not have a zone attribute, then spatial joining was used to attribute the parcels (Theobald 1999). Third, we calculated the area of each parcel in acres, after identifying and then merging together the complex parcels. Finally, we calculated the total number of units that could be built.

Fig. 12. Development in the Lower Blue Planning Basin allowed under current zoning restricted to net or developable acres (scenario CBN, Complete Build-out (net acres)). Portions of parcels with environmental constraints such as road right-of-ways, wetlands, and steep slopes were removed from the developable acres. For each parcel (not shown) in the private land (shown in pink), the number of units in each parcel is portrayed by randomly placing one point or dot per unit inside the parcel polygon.

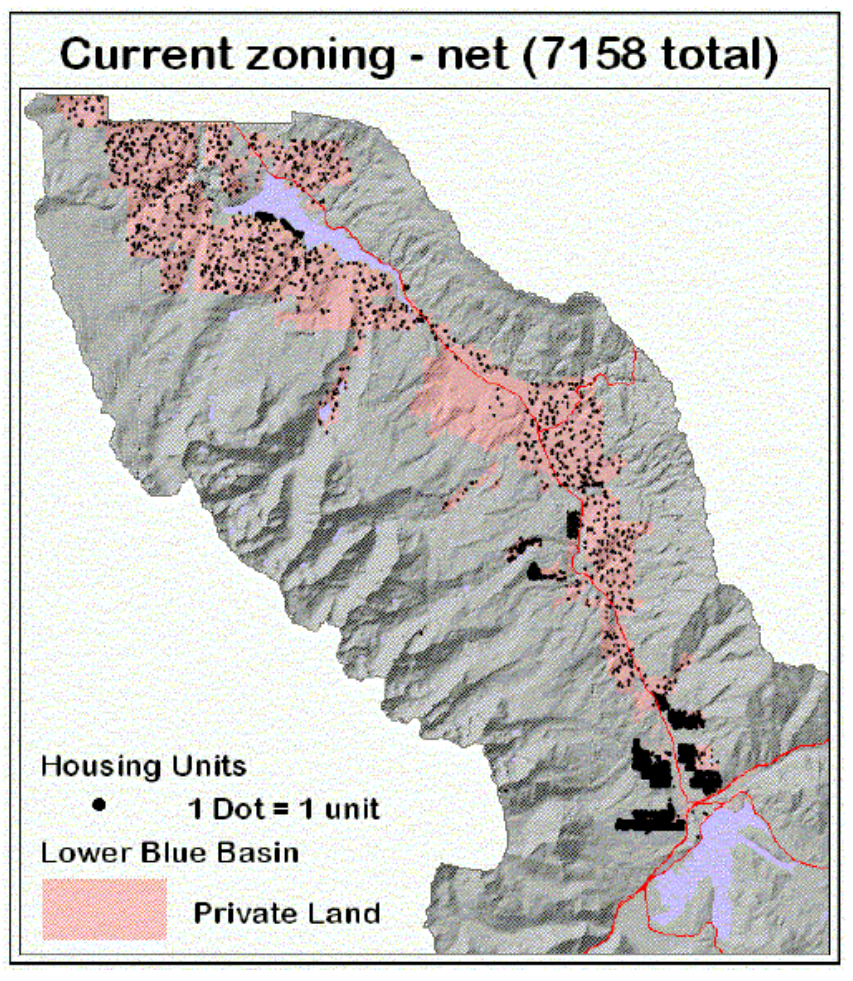

Complete Build-out (net acres): This scenario is based on the scenario $\mathrm{CB}$, but uses the developable acreage for each parcel, not the total acres (Fig. 12). Various factors typically reduce the actual amount of land available to build on, such as road right-of-ways, lot set backs, and environmental constraints (Arendt 1996). In this scenario, the net developable land was calculated by constraining developable land by wetlands, steep slopes, and road right-of-ways. [Roads were constrained by buffering with set-back distances: highways/primary roads, $50 \mathrm{ft}$; secondary arterials, 30 $\mathrm{ft}$; local roads/trails, $20 \mathrm{ft}$. Areas with slopes over 30 degrees, identified using a 30-m DEM, were removed from the parcels. Wetlands identified from lowaltitude aerial photography, buffered by $25 \mathrm{~m}$, were used to further restrict development on a parcel.] The number of units that could be developed was then based on the net acres. We used ArcView to calculate the string: "TotUnits $=($ [UperAc] $*$ [NetAcres] ).Truncate $\max 1$," where [UperAc] is the number of units per acre prescribed by the zoning and [NetAcres]. However, it is arguable, especially with large parcels (>10 acres [4.05 ha]), that these factors do not constrain the number of units. Larger parcels offer a fair amount of room for configuring a subdivision to maximize the number of units. When the building size of a building envelope approaches the size of the parcel, then it is more likely that these constraints will result in reduced numbers of units. For this reason, the remaining scenarios used the total developable area rather than the net developable area to calculate the number of units.

Fig. 13. Development in the Lower Blue Planning Basin allowed under current zoning with annexation by the Town of Silverthorne (scenario S3M, Silverthorne Three-mile Plan). Parcels identified as likely to be annexed were mapped using their future land use. For each parcel (not shown) in the private land (shown in pink), the number of units in each parcel is portrayed by randomly placing one point or dot per unit inside the parcel polygon.

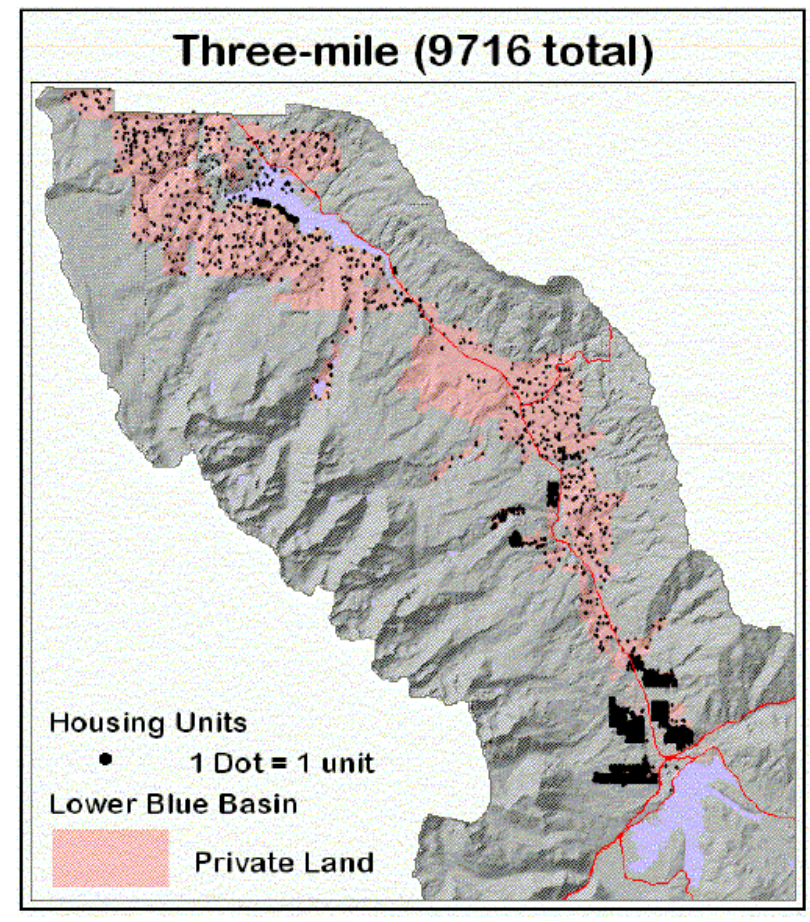


Silverthorne Three-mile Annexation: This scenario reflects the likelihood that towns and cities frequently annex adjacent, unincorporated areas (Fig. 13). Typically, this results in much higher densities in the annexed parcels. In Colorado, incorporated cities can annex unincorporated lands up to 3 miles [4.8 km] from current city boundaries. The document that specifies the parcels that would be annexed and their future land use (called "the Three-mile Plan") was acquired and the number of units were extracted for parcels that are identified in the plan (Silverthorne Planning Commission 1998).

Fig. 14. Development in the Lower Blue Planning Basin allowed under current zoning with clustered development in parcels $>70$ acres [28.3 ha] (scenario CD, Clustered Development). Because of the difficulty of locating the developed portion of a clustered development (which requires site-level planning), we simply mapped the units randomly in a parcel. Thus, the number of units accurately reflects the assumption, but the dispersed pattern shown in this graphic is potentially misleading, because the actual pattern of likely development under this scenario would be dispersed clusters of dots. For each parcel (not shown) in the private land (shown in pink), the number of units in each parcel is portrayed by randomly placing one point or dot per unit inside the parcel polygon.

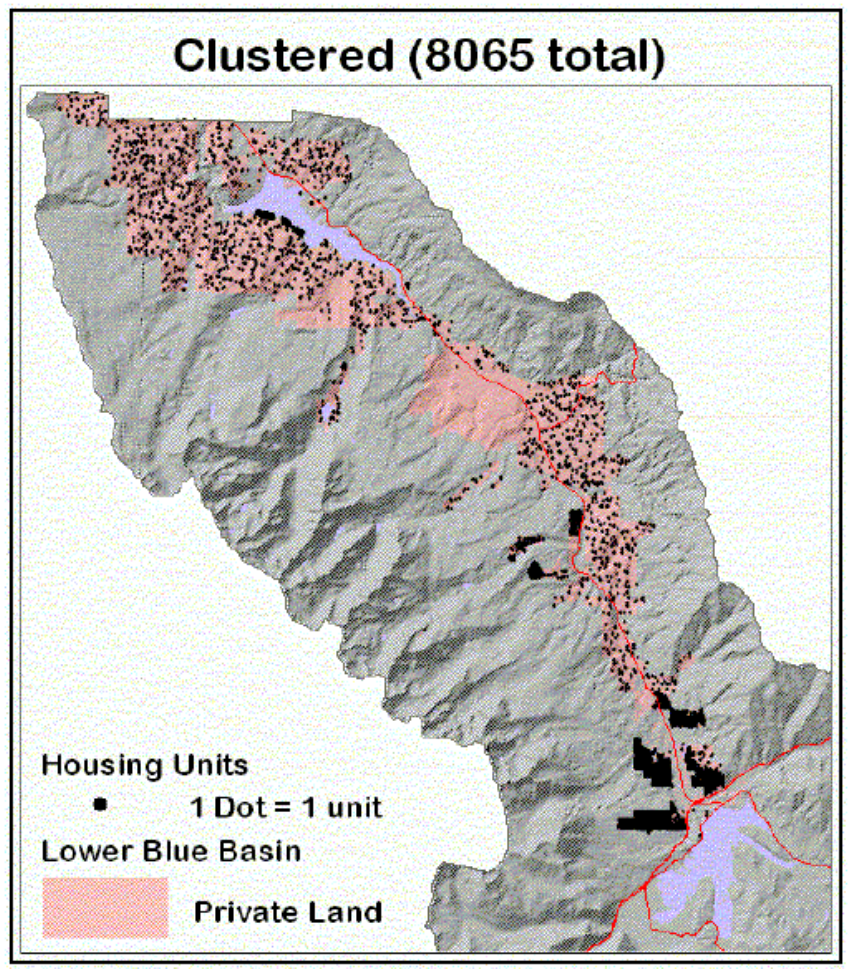

Fig. 15. Development in the Lower Blue Planning Basin allowed under current zoning with parcels zoned for a density of one per20 acres [8.1 ha] reduced to one per 35 acres [14.1 ha] (scenario DR35, Density Reduction). For each parcel (not shown) in the private land (shown in pink), the number of units in each parcel is portrayed by randomly placing one point or dot per unit inside the parcel polygon.

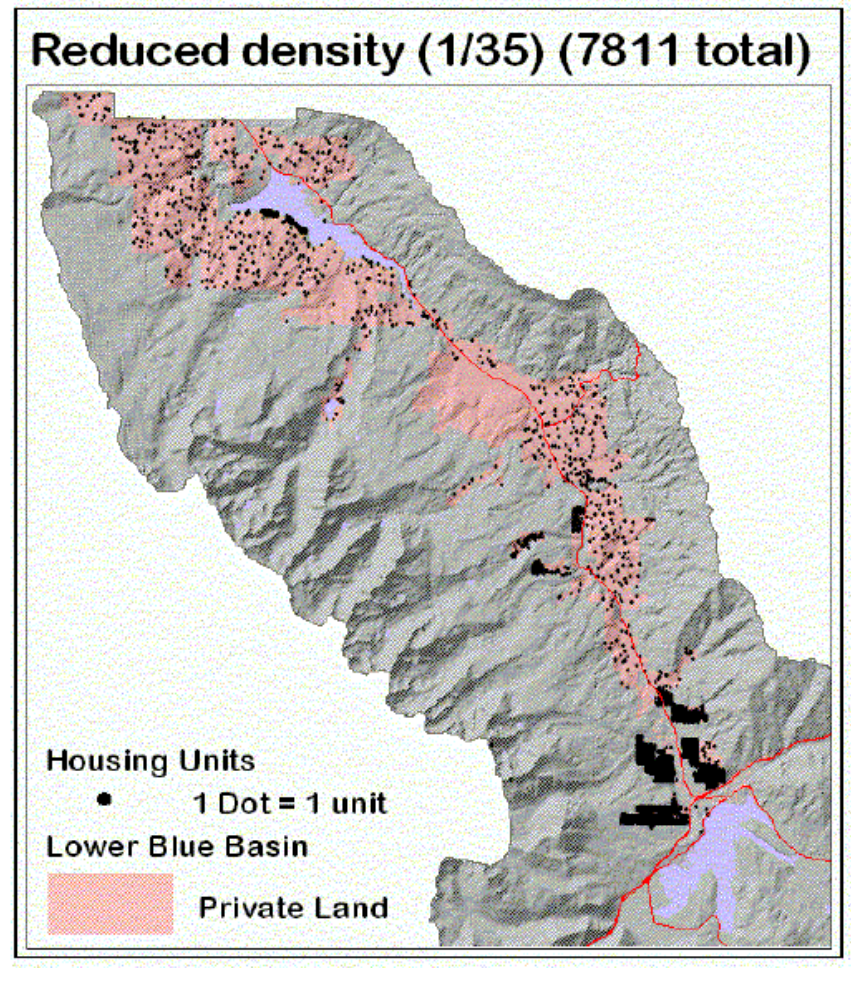

Clustered Development: Clustered development is an emerging tool for managing growth and protecting natural resources (e.g., Bowler 1997), although it was identified nearly 40 years ago as a way to conserve resources (Whyte 1964). Typically, clustered development requires an incentive to landowners by allowing additional housing units in compensation for clustering development in a portion (usually $20 \& * 8211 ; 30 \%)$ of a large (>40 acre [16.2 ha]) parcel. In Summit County, the Rural Land Use Subdivision process provides an alternative development process for rural land owners of parcels 70 acres [28.3 ha] or greater with A-1 zoning (one per 20 units) (Summit County $2000, \S 8420)$. If $85 \%$ or more of the parcel is designated as "open space," then an additional $15 \%$ of the original units can be built. These regulations have been adopted to encourage more efficient land use and to preserve agricultural lands, wildlife habitat, historic sites, scenic quality, and rural character. Site-scale planning is required to locate the developed portion of a clustered development, and is beyond the scope of this type of analysis (but see Untermann and Small 1977, Arendt 1999). Instead, we chose to allow the units to spread randomly across the entire parcel (Fig. 14). However, when we calculated the indicators, we 
reduced the impact of each housing unit in proportion to the developed:open-space ratio. That is, the impact was averaged across the whole parcel, rather than being limited to the developed area.

Fig. 16. Development in the Lower Blue Planning Basin allowed under current zoning with parcels zoned for a density of one per 20 acres [ $8.1 \mathrm{ha}$ ] reduced to one per 80 acres [32.4 ha] (scenario DR80, Density Reduction). For each parcel (not shown) in the private land (shown in pink), the number of units in each parcel is portrayed by randomly placing one point or dot per unit inside the parcel polygon.

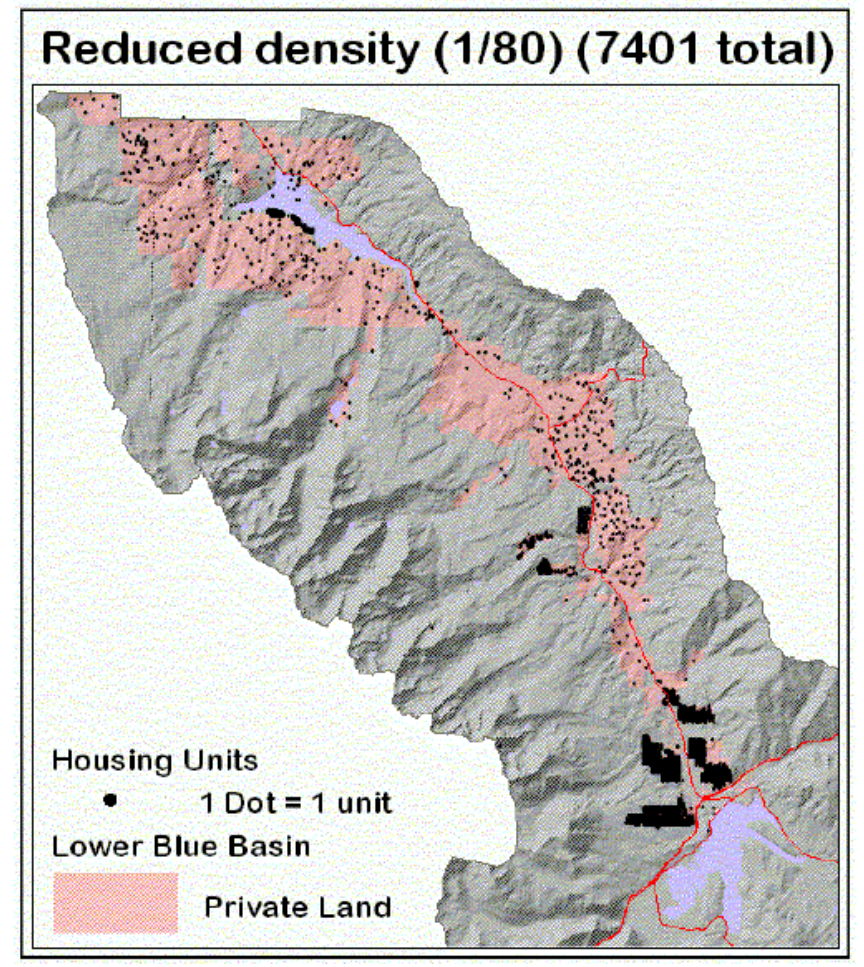

Density Reductions (one per 35 acres [14.2 ha], one per 80 acres [32.4 ha]): This scenario reflects the possibility that some rural areas might develop at a lower density than currently zoned. For example, a large part of the rural area is zoned at one unit per 20 acres [8.1 ha], but much of the recent development has occurred at a lower density, typically about one unit per 35 acres (Fig. 15). It is plausible that some areas will develop at an even lower density of one unit per 80 acres (Fig. 16).

Transfer of Development Rights (25\% and 50\%): Another land use planning tool that is growing in popularity is transfer of development rights (TDR). TDR attempts to manage the location of growth by identifying areas where development is desired, typically near urban areas with in-place infrastructure
(Porter 1997). In the LBPB, we assumed that the receiving area was located within 3 miles [4.8 km] of the Town of Silverthorne and the remainder of the Basin constituted the sending area. We arbitrarily chose two TDR situations that reflected the transfer of all units from $25 \%$ (Fig. 17) and 50\% (Fig. 18) of the parcels to within the Three-mile Plan boundary.

Fig. 17. Development in the Lower Blue Planning Basin allowed under current zoning, with $50 \%$ of units transferred to the Silverthorne area (scenario TDR25). This scenario allows Transfer of Development Rights to alter the development pattern by transferring all the units from $25 \%$ of the parcels and locating them within the Three-mile Plan boundary. For each parcel (not shown) in the private land (shown in pink), the number of units in each parcel is portrayed by randomly placing one point or dot per unit inside the parcel polygon.

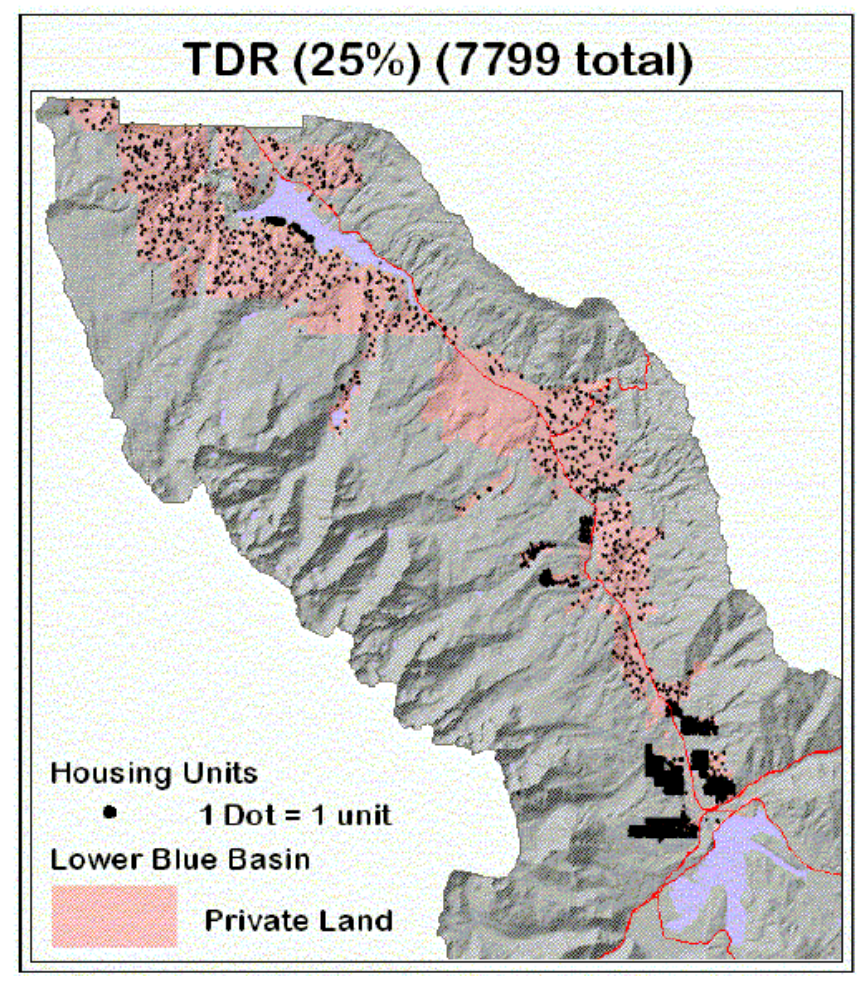

Public Land Adjustment: We also wanted to create a scenario that reflected the probable swapping of public/private land in the area. Often, the land ownership pattern, especially in the western United States, is fragmented by mining inholdings and homesteads (Theobald 2000). Many parcels are likely to be traded between the federal government and the county, in an attempt to consolidate land holdings. However, we were unable to acquire data specifying the individual parcels that were targeted for trade. Therefore, we were unable to complete this scenario. 
Fig. 18. Development in the Lower Blue Planning Basin allowed under current zoning, with 50\% of units transferred to the Silverthorne area (scenario TDR50). This scenario allows Transfer of Development Rights to alter the development pattern by transferring all the units from 50\% of the parcels and locating them within the Three-mile Plan boundary. For each parcel (not shown) in the private land (shown in pink), the number of units in each parcel is portrayed by randomly placing one point or dot per unit inside the parcel polygon.

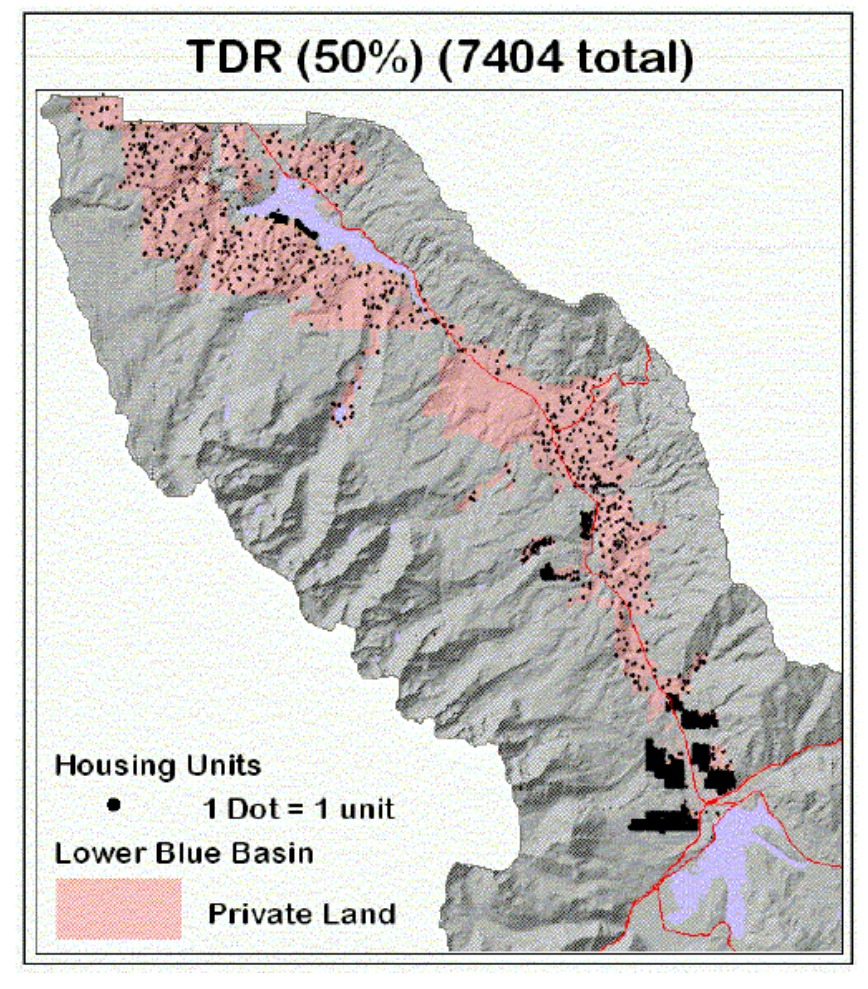

Road densities for future subdivisions were estimated by developing a relationship between housing density and road density for existing subdivisions in mountainous parts of Summit and Gunnison counties, Colorado (Table 4). For each subdivision, we did not include driveways or existing primary county roads that served other areas. We found a strong linear relationship $\left(R^{2}=0.86\right)$ between the number of acres per housing unit $(A)$ and the number of road miles per housing unit $(R)$ :

$$
R=0.0058 A+0.0216 . \quad(\text { Eq. } 1)
$$

Using Eq. 1, the prediction was 201.7 miles [324.7 $\mathrm{km}$ ] of roads for current development, which is close to the measured current road mileage (213.8 miles, excluding highways, primary roads, and trails). Because we had limited quantitative data on clustered subdivision patterns, we assumed that the road miles for clustered subdivisions would be $33 \%$ of the road miles for the number of units in the dispersed subdivision. This estimate is consistent with preliminary analysis of a few existing clustered subdivisions.

Table 4. Empirical data relating developed acres per housing unit to road miles

per housing unit in Summit and Gunnison Counties, Colorado. A linear regression

$\left(R^{2}=0.86\right)$ through these data results in the equation: $R=$ $0.0058 A+0.0216$,

where $A$ is acres per housing unit and $R$ is road miles per housing unit.

\begin{tabular}{lrrrr}
\hline \multicolumn{1}{c}{ County } & $\begin{array}{c}\text { No. ha } \\
\text { per unit }\end{array}$ & $\begin{array}{c}\text { No. km } \\
\text { per unit }\end{array}$ & \multicolumn{1}{c}{$\begin{array}{c}\text { No. acres } \\
\text { per unit }\end{array}$} & $\begin{array}{l}\text { No. road } \\
\text { miles per } \\
\text { unit }\end{array}$ \\
\hline Gunnison & 0.244 & 0.022 & 0.602 & 0.012 \\
Gunnison & 0.478 & 0.058 & 1.182 & 0.032 \\
Gunnison & 0.643 & 0.036 & 1.588 & 0.020 \\
Gunnison & 0.716 & 0.047 & 1.770 & 0.026 \\
Gunnison & 11.097 & 0.266 & 27.421 & 0.146 \\
Gunnison & 13.804 & 0.273 & 34.111 & 0.150 \\
Gunnison & 14.801 & 0.479 & 36.573 & 0.263 \\
Gunnison & 15.041 & 0.342 & 37.167 & 0.188 \\
Gunnison & 17.482 & 0.471 & 43.200 & 0.259 \\
Gunnison & 18.110 & 0.404 & 44.750 & 0.222 \\
& & & & \\
Summit & 0.379 & 0.046 & 0.937 & 0.025 \\
Summit & 0.775 & 0.062 & 1.916 & 0.034 \\
Summit & 0.811 & 0.060 & 2.004 & 0.033 \\
Summit & 1.208 & 0.076 & 2.984 & 0.042 \\
Summit & 2.788 & 0.129 & 6.889 & 0.071 \\
Summit & 7.594 & 0.335 & 18.765 & 0.184 \\
Summit & 11.890 & 0.446 & 29.380 & 0.245 \\
Summit & 18.461 & 0.704 & 45.617 & 0.387 \\
& & & & \\
\hline & & & & \\
\hline
\end{tabular}

\section{Scenario analysis}

Maps that depict development patterns resulting from the nine build-out scenarios are shown in Figs. 10-18. Currently, the Lower Basin is at about $37 \%$ build-out as compared to the Complete Build-out (total) scenario (Table 5). At the current rate of growth $(1990 \# 8211 ; 1999)$ in housing units $(7-8 \%$ per year), build-out will likely be reached in about 20 years. Using the Complete Build-out scenario (total) as a baseline, the other scenarios range from $86 \%$ to $117 \%$ of total units. An unexpected result was that the 
number of units predicted by the Complete Build-out (net) scenario was the lowest (86\%). Although current site-development restrictions are designed to limit sitelevel impacts on environmentally sensitive areas, they also appear to be a strong tool to manage the magnitude of growth. Both the Transfer of Development Rights (50\%) and Density Reductions (80 acres) scenarios would result in an $11 \%$ decrease in total units in the Lower Blue Planning Basin (excluding the Town of Silverthorne). Only 14\% of the parcels in the Lower Blue Planning Basin are eligible for clustered development, and the Clustered Development scenario would reduce the units by $3 \%$.

The predicted total miles of road in the Lower Blue Planning Basin ranged from a low of 229.5 [369.5 km] (Clustered Development) to a high of 392.0 miles [631 km] (Silverthorne Three-mile Annexation). Clearly, road miles are reduced the most $(37 \%)$ by limiting the roads associated with 35-acre development. This disproportionate effect of low-density development is also shown by the fact that although the Complete Build-out (net) scenario has $14 \%$ fewer units, it resulted in only a $7 \%$ reduction in road miles. In contrast, road miles increased by $8 \%$ in the Silverthorne Three-mile Annexation scenario, but this probably reflects an overestimation of road miles because more urban development requires fewer roads than the average figure represented in the prediction.

Roughly 135,000 acres [54,675 ha] of Summit County (34\%) were identified as Critical Habitat. As is typical of many counties in the West, much of Summit County (80\%) is public-land. However, about $30 \%$ of the Critical Habitat is found on private land. Much of the higher value composite Critical Habitat (with more than one factor) occurs on private land; private land contributes $32 \%$ of the factor-weighted Critical Habitat, even though it constitutes only $20 \%$ of the actual area. Moreover, $60 \%$ of the Critical Habitat is on or within $400 \mathrm{~m}$ of private land. These results clearly show that private lands on a county basis contain and influence a disproportionate share of the Critical Habitat. About 39\% of the Critical Habitat within the Lower Blue Planning Basin is on private land, and about $50 \%$ of the private land in the Lower Blue Planning Basin is occupied by Critical Habitat (Fig. 19).

Fig. 19. Private and public acreage of critical habitat in the Lower Blue Planning Basin, grouped by the number of factors contributing to the composite critical habitat map. The four factors included in the composite critical habitat map are rare vegetation types, sensitive and rare species habitat, high neighborhood species richness, and habitat for economically important species. Roughly $50 \%$ of the private land in the Lower Blue Planning Basin is occupied by Critical Habitat.

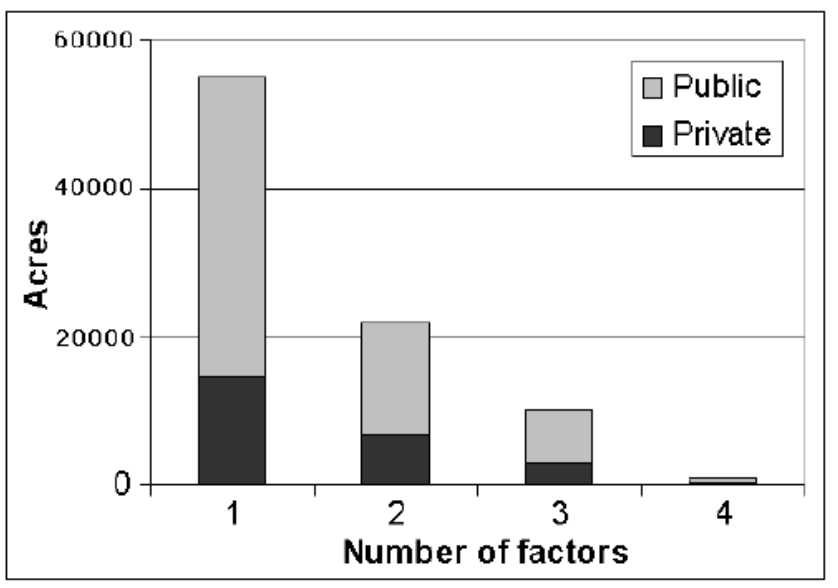

Fig. 20. Difference between maximum and minimum disturbance zone effects, calculated for each scenario. Much of the Lower Blue Planning Basin is composed of areas with lower effect difference between scenarios, so that the density and pattern of development make relatively little difference in the impact on Critical Habitat. Areas with higher effect range (e.g., 50\&*8211;100\%) are high "leverage points," where the choice of development scenario may strongly influence future effects of development on Critical Habitat. The map shows distance from locations of Critical Habitat to the nearest urban location for the 1999 development pattern. Near distances (in orange) depict locations that are relatively close to urban areas.

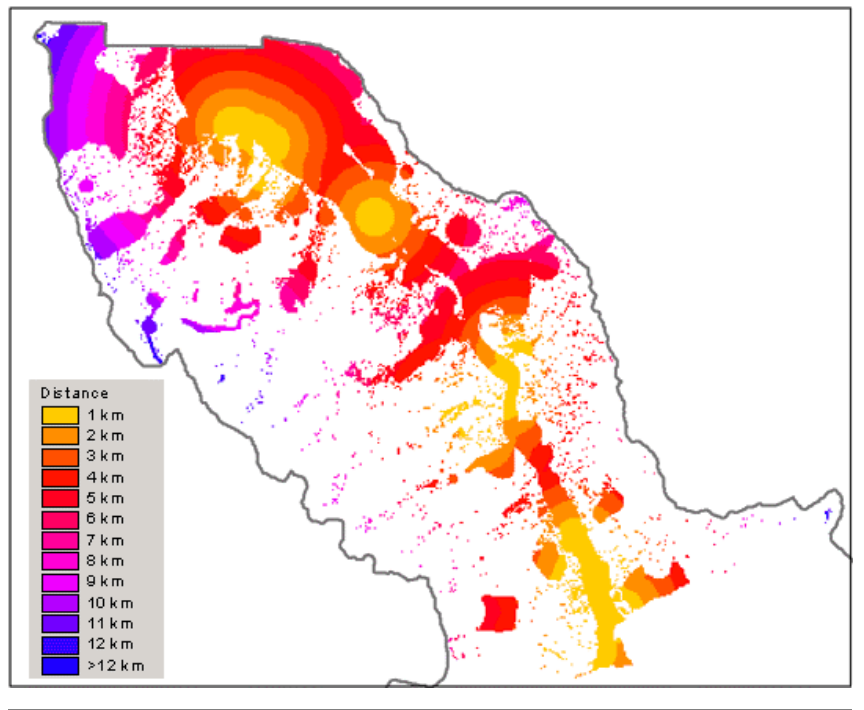

The Current Development scenario affects 924 acres [374.2 ha] of Critical Habitat, whereas the Build-out 
scenarios range from a low of 3373 acres[1366 ha] (Density Reduction, 80) to a high of 5188 acres [2101 ha] (Transfer of Development Rights, 25\%), a 365\% and $561 \%$ increase, respectively (Table 5). The scenarios Density Reduction (80), Clustered Development, and Transfer of Development Rights (50), would probably decrease the impact as compared to the "business as usual" Complete Build-out scenario, whereas the scenarios Density Reduction (35), Silverthorne Three-mile Annexation, and Transfer of Development Rights (25) would probably increase the impact. Because it is important to examine how development is likely to affect particularly important locations of Critical Habitat, we also computed the impact weighted by the number of factors (by multiplying the area by the number of factors). The ratios (as compared to the current status) ranged from $377 \%$ (Clustered Development) to $621 \%$ (Transfer of Development Rights, 25). This shows that the area will increase by 3-5 times, and much of the most important areas of Critical Habitat also will be disproportionately impacted.

Generally, the basin was relatively unfragmented by urban levels of development. There was little difference between the average distance $(\sim 3.7-3.8 \mathrm{~km})$ from Critical Habitat to urban areas defined by the different scenarios, due to the relatively isolated and fixed positions of cities within the Lower Blue Planning Basin (Fig. 20). However, the Basin was substantially fragmented under the assumption that areas with housing densities as low as 1 unit per16 ha (40 acres) hinder species movement through the landscape (Fig. 21). The average distance from Critical Habitat to developed areas in 1999 was $2.3 \mathrm{~km}$, but this declines sharply to $<1 \mathrm{~km}$ for most development scenarios. The fragmentation of Critical Habitat was reduced considerably $(1.9 \mathrm{~km})$ for the Transfer of Development Rights (50) and Density Reduction (80) development patterns, chiefly because large expanses in the middle portion of the basin no longer were fragmented (compare Fig. 22 and Fig. 23). We were unable to model the fragmentation pattern for the Clustered Development scenario because we could not easily establish the location of the developed portion within a given parcel without site-level data and further assumptions. We presume that fragmentation would be lower than in the Density Reduction (35) scenario (i.e., higher average distance) for the exurban density assumption, because new houses would not be dispersed throughout a parcel. Also, fragmentation would also remain low for the urban density assumption, because most developed portions of clustered subdivisions occur at a density of roughly 1 house/2 ha. However, if there is good biological reason to assume that housing densities between urban and exurban (e.g., 1 house/2 ha) fragment the landscape, then the Clustered Development scenario (unlike the other scenarios) might result in an extremely fragmented landscape, with average distances lower than in any other scenario.

Fig. 21. Map of distance from locations of Critical Habitat to the nearest exurban location for 1999 development. Compared to Fig. 20 (urban development), much more of the Lower Blue Planning Basin is shown in "near" colors of orange and red.

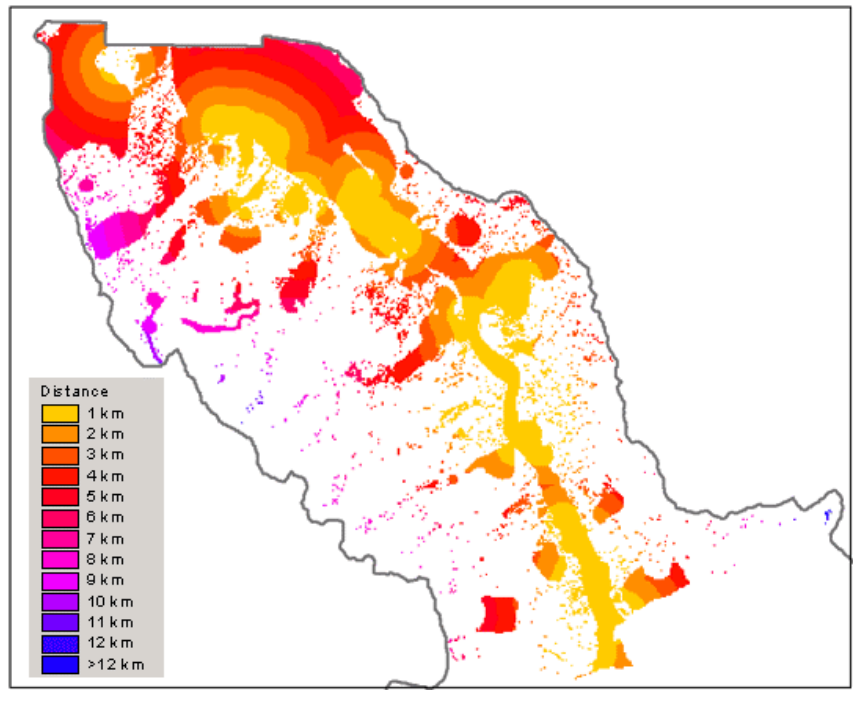

Fig. 22. Map of distance from locations of Critical Habitat to the nearest exurban location depicted in the Density Reduction (35) scenario. The vast majority of the Lower Blue Planning Basin, especially the river corridor running from upper left to lower right, is strongly fragmented by development.

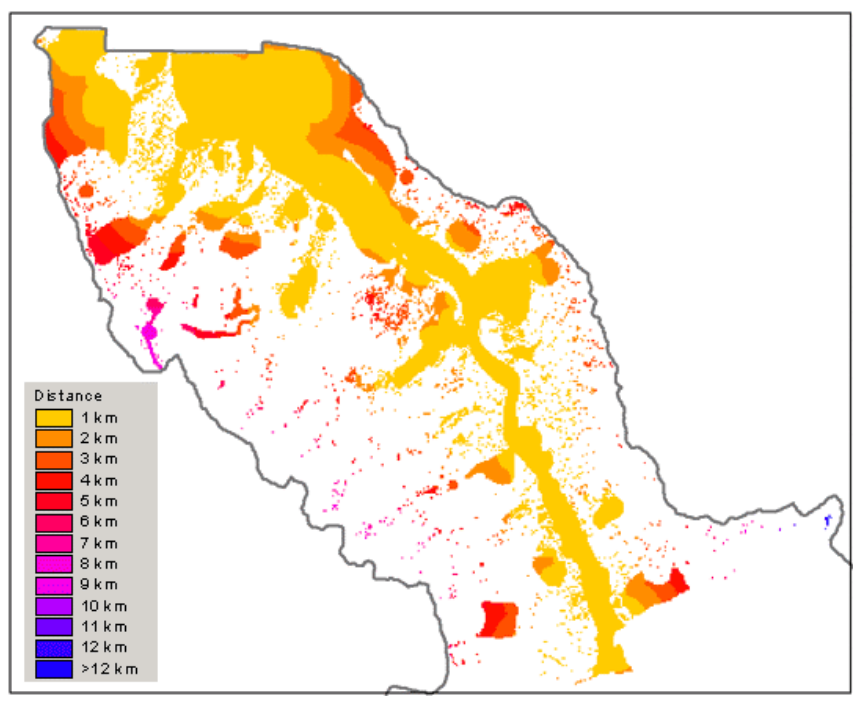


Fig. 23. In contrast to Fig. 22, fragmentation of Critical Habitat is reduced, as depicted by distance to the nearest exurban location in the Density Reduction (80) scenario. This graphically shows the strong sensitivity of the Lower Blue Planning Basin to the assumed fragmentation effects of exurban development. That is, there are several zones in the valley bottom where red values $(2-4 \mathrm{~km})$ separate more dense locations. These would offer useful locations to maintain connectivity across (perpendicular to) the Lower Blue valley bottom.

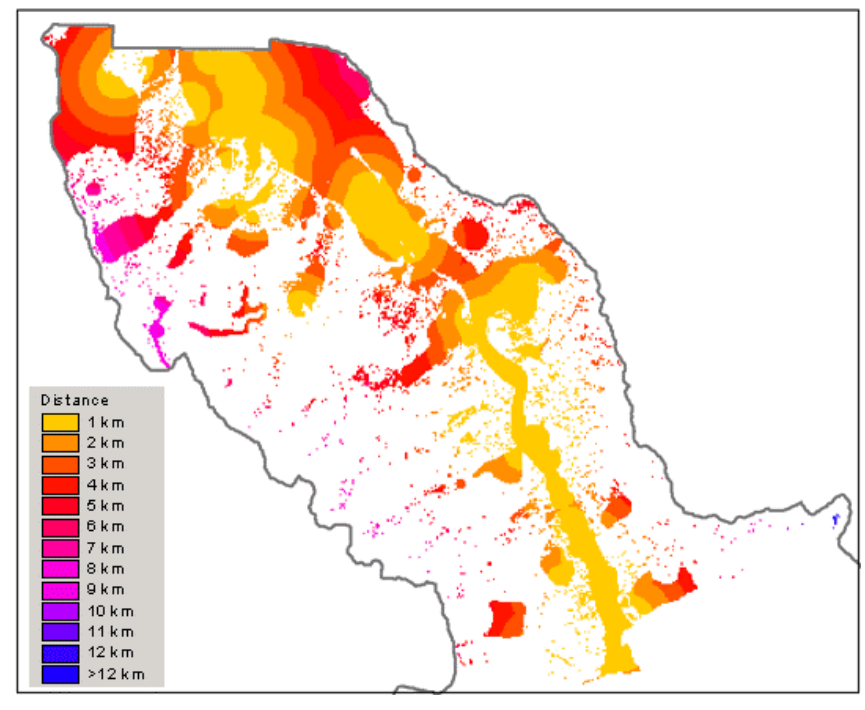

At a finer scale, the Critical Habitat map was used as a filter to identify undeveloped parcels that, if developed, would probably impact areas of Critical Habitat. In the Lower Blue Planning Basin, only 20\% of private parcels that could be further developed intersect Critical Habitat, but these developable parcels occupy $90 \%$ of the private land in the Planning Basin. That is, this is a high-leverage situation in which a relatively few decisions (and decision makers) will influence a large portion of the Planning Basin.

We used a 100-m disturbance zone to model how the different development densities and patterns produced by the scenarios would be likely to affect Critical Habitat. Nearly $30 \%$ of the parcels that intersect Critical Habitat have development densities and patterns that would probably result in parcels being affected by up to $50 \%$. There is a strong threshold at around $20 \%$ affected, where the majority (75\%) of the developable area changes. In order to identify the parcels where there was a large difference in effects, depending on the scenario, and to facilitate comparison of scenarios, we calculated for each parcel the range of effects (Fig. 24). That is, we subtracted the minimum from the maximum effect value produced by the different scenarios. A range of 0 meant that all scenarios resulted in the same effect on Critical Habitat. A larger range (e.g., 50-100\%) meant that there was large difference in the potential effect of development, depending on the development scenario. For much of the Lower Blue Planning Basin, there is little difference between scenarios, but a few isolated parcels have a large range and, hence, should be examined in further detail to determine which scenarios are more beneficial. Generally, the scenarios are useful at a broad scale to target key locations, but at a finer scale (per parcel), there is lower utility and site-level analysis is required to fully explore the differential effects of locating development at various locations and configurations.

Fig. 24. Difference between maximum and minimum disturbance zone effects, calculated for each parcel.

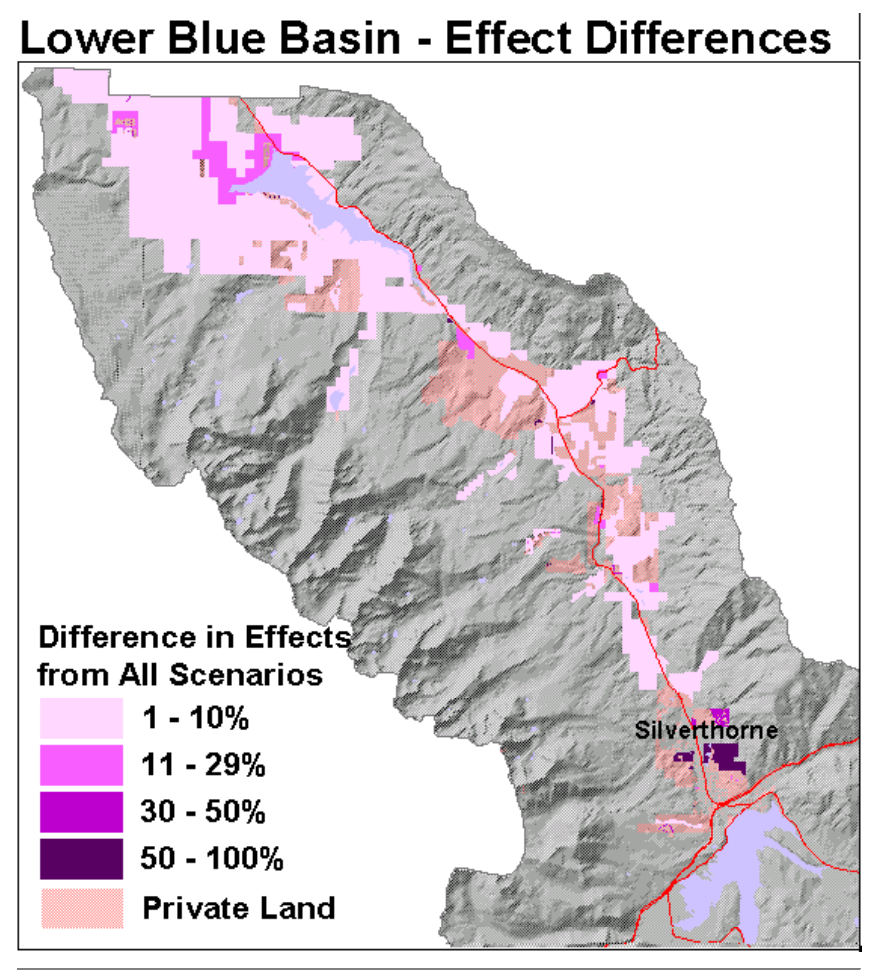

The potential impact of development on biodiversity can also be evaluated in relation to some development goal. If the development goal is to minimize impacts on biodiversity, then clustered development (especially with judicious placement of the developed portion) and reducing density (one per 80 ) is the best direction. However, if the development goal is to maximize the number of units while minimizing the area of Critical Habitat effected, then the scenarios that modify development in rural (low-density) areas are most efficient, either by decreasing the footprint of 
development through Clustered Development or by simply reducing the number of units that contribute disproportionately to impacts (Density Reduction, 80). Indeed, the clustered development scenario stands out as the primary method for reducing potential impacts of development. However, this recommendation is based on the assumption that thorough site-level review will ensure that the developed portion of clustered development is situated to minimize impact on Critical Habitat. Our study did not account for impacts associated with "clustered sprawl" such as increased traffic along rural roads (Daniels 1999).

A synthetic scenario that draws on the beneficial aspects from a number of scenarios that might result in the least impact would look like the following. First, the existing set-backs and environmental constraints that limit the total number of units should be rigorously enforced. Second, a Transfer of Development Rights program that concentrates development in established service areas and away from habitat will lower impacts and should be pursued. Third, cluster development with careful site-level planning should substantially reduce the miles of roads needed and minimize disturbance on habitat.

\section{Evaluation and monitoring}

The composite Critical Habitat map reflected the broad goals for conservation of biodiversity identified by the stakeholders. These goals, especially protection of rare vegetation and habitat, are notable for their departure from typical private land use planning efforts, which often simply list species to protect (usually dominated by charismatic mammals). A more challenging aspect has been to integrate a monitoring scheme into the planning process. The Summit County Wildlife Task Force recently recommended that field-based monitoring be included in the master plan, but implementation has not been worked out.

\section{DISCUSSION}

The framework that we describe here provides an integrated approach to informing private land use planning activities with biological information. This approach has been useful in Summit County for understanding the consequences of development for wildlife and biodiversity, for evaluating the differential effects associated with various land use planning actions, and for informing private land use decision making. It is also important that this approach complements the field experience and expertise of local professional biologists and wildlife managers. Better support for these biologists is critical for effective conservation of private land.

However, a number of challenges remain to implement fully the details of this approach. One of the problems we encountered in adequately modeling development was how to select specific parcels to be developed. For example, if a reasonable guess is that only $25 \%$ of parcels eligible will be cluster developed, then which parcels should be selected? Rather than randomly selecting parcels likely to be built, or developing a more complicated model to predict the probability of development, we chose to apply a scenario's assumption across all applicable parcels. For the cluster development scenario, all eligible parcels are modeled as clustered. We do not presume that, in reality, any one planning action will affect all eligible parcels. Instead, we believe that this approach will give more insight into the strengths and weaknesses of each scenario.

A second difficulty was that modeling some scenarios required site-level patterns to be specified. For example, where the location of development occurs in a cluster development, is important in understanding any potential impacts. When possible, we avoided making modeling assumptions at the site level.

A third challenge was how to best portray the scenarios cartographically. We chose to use randomly located points (dot maps) within each parcel to reflect the number of units that could be built. This allowed the user to easily see different densities within a map (e.g., towns vs. rural areas) and to easily compare patterns between scenarios. Also, we did not show parcel boundaries, to simplify the map visually, and to emphasize the pattern of development between parcels, rather than the pattern within a parcel. Mapping development patterns in this way helps the general public to appreciate general patterns of development and impacts, rather than reinforcing the natural inclination to focus solely on a specific parcel or in a person's backyard.

In this paper, we have been less concerned with precise measurement of the absolute impacts of development on habitat, and more concerned with ways to evaluate the relative impacts of development that would likely result from different planning policies and tools. We have preferred "... approximate answers to the right questions, not precise answers to the wrong questions" (Holling 1997). Although 
understanding the absolute impacts of development on a particular species or community is an important goal, we must also recognize the pressing need to act despite a paucity of data, limited understanding, and the species-specific nature of impacts. However, we face a final challenge: in addition to comparing the identified set of realistic, plausible development scenarios against one another, we need to establish a baseline against which all scenarios should be judged, to determine whether enough Critical Habitat is intact for proper functioning. In addition to identifying the best scenario, we need to judge whether each scenario is ecologically sound or not. The traditional baseline in planning reflects "business as usual" (in this case, the Complete Build-out scenarios). Our results clearly distinguished those scenarios that will increase the level of impact from those that will reduce the impact of new development. Yet, from a biological perspective, a more meaningful baseline is needed to assess whether the ecosystem is likely to remain intact in the face of future development. This is a demanding, yet critical task.

\section{Speculation}

Two aspects of our approach are particularly strong impediments to the application of conservation ecology to conservation on private lands. First, although stakeholders and scientific colleagues pressed us with the need to evaluate the scenarios in terms of fragmentation, and we responded with what we believe is a robust, useful metric, we continue to remain cautious about overly simplified measures that do not capture fragmentation in functional terms. Further development of a robust metric of fragmentation for land use planning applications remains a priority for conservation planning.

Second, we have provided only the barest of details on how to implement evaluation and monitoring in the planning process, to reflect the ideas of adaptive management. One of the greatest challenges to fully developing adaptive management on private lands is the idea of fairness and predictability that underlies private land ownership. That is, landowners typically demand that the planning process be fair, transparent, and predictable, so that issues that may preclude modification of land use can be anticipated. However, this perspective is diametrically opposed to the iterative, "learn as you go" process of adaptive management. Changing land use regulations to reflect better information and improved understanding may be reasonable to scientists, but makes the planning process less predictable. Moreover, gaining access from private landowners for monitoring rare species is difficult because landowners fear that this information will be used to limit their ability to develop in the future. Rather, we should strive to develop new uses for biological information that are not perceived to limit a land developer's ability, but rather to assist him/her in intelligent design of subdivisions and development. We must seize opportunities to enhance habitat through intelligent design, rather than reinforcing the notion that human actions will always and necessarily degrade the natural environment.

Responses to this article can be read online at: http://www.consecol.org/vol6/iss1/art5/responses/index.html.

\section{Acknowledgments:}

Many of the ideas presented here were developed through discussions with Brian Lorch, Charmin Bogart, Mark Truckee, Rich Ferris, and Trip McLaughlin from the Summit County Planning Department, and with Tom Kroening and Pam Schnurr from the Colorado Division of Wildlife. The authors also thank George Wallace for his helpful comments on an earlier draft, and reviewers for helpful suggestions. This work was funded in part by Great Outdoors Colorado, the Colorado Division of Wildlife, and the David H. Smith Fellowship Program of The Nature Conservancy.

\section{LITERATURE CITED}

Arendt, R. 1996. Conservation design for subdivisions: a practical guide to creating open space networks. Island Press, Washington, D.C., USA.

Arendt, R. 1999. Growing greener: Putting conservation into local plans and ordinances. Island Press, Washington, D.C., USA.

Bean, M. J., and D. S. Wilcove. 1997. The private-land problem. Conservation Biology 11:1-2.

Beatley, T. 1994. Habitat conservation planning: Endangered species and urban growth. University of Texas Press, Austin, Texas, USA.

Beatley, T., and K. Manning. 1997. The ecology of place: Planning for environment, economy, and community. Island Press, Washington, D.C., USA.

Bowler, C. 1997. Farmland preservation and the cluster zoning model. Journal of the American Planning 
Association 63(1):127-128.

CNHP. 1999. Conservation status handbook: Colorado's animals, plants, and plant communities of special concern. Colorado Natural Heritage Program, Fort Collins, Colorado, USA.

Cort, C. A. 1996. A survey of the use of Natural Heritage data in local land-use planning. Conservation Biology 10:632-637.

Crist, P. J., T. W. Kohley, and J. Oakleaf. 2000. Assessing land-use impacts on biodiversity using an expert systems tool. Landscape Ecology 15(1):47-62.

Dale, V. H., S. Brown, R. A. Haeuber, N. T. Hobbs, N. Huntly, R. J. Naiman, W. E. Riebsame, M. G. Turner, and T. J. Valone. 2000. Ecological principles and guidelines for managing the use of land: a report from the Ecological Society of America. Ecological Applications 10:639-670.

Daniels, T. 1999. What to do about rural sprawl? Presented at the American Planning Association Conference, 28 April 1999, Seattle, Washington, USA.

Duerkson, C. J., N. T., Hobbs, D. L. Elliott, E. Johnson, and J. R. Miller. 1997. Managing development for people and wildlife: A handbook for habitat protection by local governments. American Planning Association, PAS \#470/471. Chicago, Illinois, USA.

Forman, R. T. T., and L. E. Alexander. 1998. Roads and their major ecological effects. Annual Review of Ecology and Systematics 28:207-231.

GAO (General Accounting Office). 1994. Endangered Species Act: information on species protection on nonfederal lands. GAO/RCED-95-16.

Gross, J. E., and C. P. Melcher. 1998. COVERS: Identifying species at risk and setting priorities for conservation of vertebrates in Colorado. Unpublished report submitted to the Colorado Division of Wildlife, Fort Collins, Colorado, USA.

Haney, A., and L. P. Rebecca. 1996. Adaptive management for sound ecosystem management. Environmental Management 20:879-886.

Hobbs, N. T., D. M. Theobald, J. Zack, and T. A. Bearly. 1998. A system for conservation planning: Access to stateof-the-art information on wildlife, plants, and natural communities in Colorado. [Online, URL: http://www.ndis.nrel.colostate.edu/.]

Holling, C. S. 1978. Adaptive environmental assessment and management. John Wiley, New York, New York, USA.

Holling, C. S. 1997. The inaugural issue of Conservation Ecology. Conservation Ecology 1(1):1. [Online] URL: http://www.consecol.org/Journal/vol1/iss1/art1
Hulse, D., M. Flaxman, D. Richey, L. Goorjian, D. Diethelm, K. Freemark, D. White, C. Humman, J. Eilers, J. Bernert, and S. Radosevich. 1995. Possible futures for the Muddy Creek Watershed, Benton County, Oregon. Institute for a Sustainable Environment, University of Oregon, Eugene, Oregon, USA. http://ise.uoregon.edu/Muddy/Muddy_abstract.html

Klosterman, R. E. 1999. The What if? Collaborative planning support system. Environment and Planning B: Planning and Design 26:393-408.

Lacy, J. 1992. Manual of build-out analysis. Center for Rural Massachusetts. Amherst, Massachusetts, USA.

Landis, J. D. 1995. Imagining land use futures: applying the California Urban Futures Model. Journal of the American Planning Association 61:438-457.

Lee, K. N. 1993. Compass and gyroscope: Integrating science and politics for the environment. Island Press, Washington, D.C., USA.

McKinney, L. D., and R. Murphy. 1996. When biologists and engineers collide: Habitat conservation planning in the middle of urbanized development. Environmental Management 20(6):955-961.

Meredith, T. 1996. Linking science and citizens: Exploring the use of geographic information and analysis in community-based biodiversity conservation initiatives. Human Ecology Review 3:231-237.

Noss, R. F., M. A. O'Connell, and D. D. Murphy. 1997. The science of conservation planning: habitat conservation under the Endangered Species Act. Island Press, New York, New York, USA.

Ringold, P. L., B. Mulder, J. Alegria,, R. L. Czaplewski, T. Tolle, and K. Burnett. 1999. Establishing a regional monitoring strategy: The Pacific Northwest forest plan. Environmental Management 23:179-192.

Ripple, W. J., G. A. Bradshaw, and T. A. Spies. 1991. Measuring forest landscape patterns in the Cascade Range of Oregon, USA. Biological Conservation 57(1):73-88.

Rockwood, P. 1995. Landscape planning for biodiversity. Landscape and Urban Planning 31:379-385.

Shindler, B., and K. A. Cheek. 1999. Integrating citizens in adaptive management: a prepositional analysis. Conservation Ecology 3(1):9. [Online] URL: http://www.consecol.org/Journal/vol3/iss 1/art9

Silverthorne Planning Commission. 1998. Town of Silverthorne, Colorado: Three-mile annexation plan. Silverthorne, Colorado, USA.

Stein, B. A., L. S. Kutner, and J. S. Adams, editors. 1999. Precious heritage: The status of biodiversity in the United States. Oxford Press, Oxford, UK. 
Steinitz, C., M. Binford, P. Cote, T. Edwards, Jr., S. Ervin, R. T. T. Forman, C. Johnson, R. Kiester, D. Mouat, D. Olson, A. Shearer, R. Toth, and R. Wills. 1996. Biodiversity and landscape planning: Alternative futures for the region of Camp Pendleton, California. Graduate School of Design, Harvard University, Camdridge, Massachusetts, USA.

Summit County. 2000. Summit County Land Use and Development Code. Summit County, Frisco, Colorado, USA. [Online] URL: http://www.co.summit.co.us/divisions/ commdev/planning/LUC/toc.htm

Theobald, D. M. 1999. GIS Concepts and ArcView methods. Conservation Planning Technologies, Fort Collins, Colorado, USA.

Theobald, D. M. 2000. Fragmentation by inholdings and exurban development. Pages 155-174 in R. L. Knight, F. W. Smith, S. W. Buskirk, W. H. Romme, and W. L. Baker, editors. Forest fragmentation in the central Rocky Mountains. University Press of Colorado, Boulder, Colorado, USA.

Theobald, D. M., N. T. Hobbs, T. Bearly, J. Zack, T. Shenk, and W. E. Riebsame. 2000. Incorporating biological information into local land-use decision making: Designing a system for conservation planning. Landscape Ecology 15(1):35-45.

Theobald, D. M., and N. T. Hobbs. 1998. Forecasting rural land use change: A comparison of regression- and spatial transition-based models. Geographical and Environmental Modelling 2(1):57-74.

Theobald, D. M., J. M. Miller, and N. T. Hobbs. 1997. Estimating the cumulative effects of development on wildlife habitat. Landscape and Urban Planning 39(1):2536.

Tischendorf, L., and L. Fahrig. 2000. On the usage and measurement of landscape connectivity. Oikos 90:7-19.

Turner, M. G., R. H. Gardner, and R. V. O'Neill. 2001. Landscape Ecology in Theory and Practice. Springer, New York, New York, USA.

Untermann, R., and R. Small. 1977. Site planning for cluster housing. Van Nostrand Reinhold, New York, New York, USA.

Walters, C. J. 1986. Adaptive management of renewable resources. Macmillian, New York, New York, USA.

White, D., P. G. Minotti, M. J. Barczak, J. C. Sifneos, K. E. Freemark, M. V. Santelmann, C. F. Steinitz, A. R. Kiester, and E. M. Preston. 1997. Assessing risks to biodiversity from future landscape change. Conservation Biology 11:1-13.

Whyte, W. H. 1964. Cluster development. American Conservation Association, New York, New York, USA. 